\title{
Remote Sensing of Liquid Water and Ice Cloud Optical Thickness and Effective Radius in the Arctic: Application of Airborne Multispectral MAS Data
}

\author{
Michael D. King,* Steven Platnick, ${ }^{+}$Ping Yang, \# G. Thomas Arnold, ${ }^{@}$ Mark A. Gray, @ \\ JÉrôme C. Riedi, \& Steven A. Ackerman, ** and Kuo-Nan Liou ++ \\ *Earth Sciences Directorate, NASA Goddard Space Flight Center, Greenbelt, Maryland \\ ${ }^{+}$Laboratory for Atmospheres, NASA Goddard Space Flight Center, Greenbelt, Maryland \\ \#Department of Atmospheric Sciences, Texas A\&M University, College Station, Texas \\ ${ }^{@}$ L3 Communications, Government Services, Inc., Landover, Maryland \\ \&Laboratoire d'Optique Atmosphérique, Université des Sciences et Technologies de Lille, Villeneuve d'Ascq, France \\ **Department of Atmospheric and Oceanic Sciences, University of Wisconsin-Madison, Madison, Wisconsin \\ ${ }^{+}$Department of Atmospheric Sciences, University of California, Los Angeles, Los Angeles, California.
}

(Manuscript received 7 October 2003, in final form 18 November 2003)

ABSTRACT

\begin{abstract}
A multispectral scanning spectrometer was used to obtain measurements of the bidirectional reflectance and brightness temperature of clouds, sea ice, snow, and tundra surfaces at 50 discrete wavelengths between 0.47 and $14.0 \mu \mathrm{m}$. These observations were obtained from the NASA ER-2 aircraft as part of the First ISCCP (International Satellite Cloud Climatology Project) Regional Experiment (FIRE) Arctic Clouds Experiment, conducted over a $1600 \mathrm{~km} \times 500 \mathrm{~km}$ region of the north slope of Alaska and surrounding Beaufort and Chukchi Seas between 18 May and 6 June 1998. Multispectral images in eight distinct bands of the Moderate Resolution Imaging Spectroradiometer (MODIS) Airborne Simulator (MAS) were used to derive a confidence in clear sky (or alternatively the probability of cloud) over five different ecosystems. Based on the results of individual tests run as part of this cloud mask, an algorithm was developed to estimate the phase of the clouds (liquid water, ice, or undetermined phase). Finally, the cloud optical thickness and effective radius were derived for both water and ice clouds that were detected during one flight line on 4 June.

This analysis shows that the cloud mask developed for operational use on MODIS, and tested using MAS data in Alaska, is quite capable of distinguishing clouds from bright sea ice surfaces during daytime conditions in the high Arctic. Results of individual tests, however, make it difficult to distinguish ice clouds over snow and sea ice surfaces, so additional tests were added to enhance the confidence in the thermodynamic phase of clouds over the Chukchi Sea. The cloud optical thickness and effective radius retrievals used three distinct bands of the MAS, with a recently developed 1.62- and 2.13- $\mu \mathrm{m}$-band algorithm being used quite successfully over snow and sea ice surfaces. These results are contrasted with a MODIS-based algorithm that relies on spectral reflectance at 0.87 and $2.13 \mu \mathrm{m}$.
\end{abstract}

\section{Introduction}

A knowledge of cloud radiative properties and their variation in space and time is especially crucial to the understanding of the radiative forcing of climate. High quality multispectral imagery acquired from high-altitude aircraft or satellite platforms is the most efficient and reliable means of fulfilling these observational requirements. Between 18 May and 6 June 1998, the National Aeronautics and Space Administration (NASA) ER-2 high-altitude research aircraft conducted 11 research flights over the north slope of Alaska and the surrounding Beaufort and Chukchi Seas as part of the First ISCCP (International Satellite Cloud Climatology

Corresponding author address: Dr. Michael D. King, NASA Goddard Space Flight Center, Code 900, Greenbelt, MD 20771.

E-mail: michael.d.king@nasa.gov
Project) Regional Experiment-Arctic Clouds Experiment (FIRE ACE). The NASA ER-2 aircraft was equipped with seven sensors, among which the Moderate Resolution Imaging Spectroradiometer (MODIS) Airborne Simulator (MAS; King et al. 1996) was designed to obtain measurements that simulate those obtained from MODIS, a 36-band spectroradiometer launched aboard the Earth Observing System (EOS) Terra (King and Herring 2000) and Aqua (Parkinson 2003) spacecraft.

The strategy for FIRE ACE included spaceborne remote sensing (polar-orbiting satellites), high-altitude remote sensing (NASA ER-2 at $\sim 20 \mathrm{~km}$ ), lower-altitude remote sensing and in situ measurements [University of Washington CV-580, National Center for Atmospheric Research (NCAR) C-130Q, and Canada's National Research Council Convair 580 (NRC CV-580) aircraft], ground-based measurements (radiation, clouds, meteo- 
rology, and surface fluxes), and modeling studies (cf. Curry et al. 2000). FIRE ACE took advantage of, and overlapped with, the Surface Heat Budget of the Arctic Ocean (SHEBA) experiment, which largely consisted of surface measurements on and around the Canadian Coast Guard icebreaker Des Groseilliers that drifted throughout the Beaufort and Chukchi Seas over a 12month period. The ER-2 was based in Fairbanks and deployed over the north slope of Alaska and the nearby Arctic Ocean and typically overflew the surface Atmospheric Radiation Measurement (ARM) site in Barrow, Alaska, en route to and from the SHEBA ice station.

The main objectives of the ER-2 included (i) comparing the spectral properties of sea ice, tundra, and cloud layers; (ii) collecting MAS data to verify the MODIS cloud mask algorithm for distinguishing clouds from snow and sea ice surfaces in polar regions; (iii) collecting data for retrieving cloud radiative and microphysical properties over snow and sea ice surfaces during summer daytime conditions; (iv) determining the radiative energy budget of clouds and sea ice in polar regions; and (v) comparing high-altitude remote sensing and ground-based observations of clouds and clear sky in polar regions, especially over the SHEBA and ARM long-term ground-based remote sensing sites.

Clouds are generally characterized by higher reflectance and lower temperature than the underlying surface. As such, simple visible and infrared window threshold approaches would appear to offer considerable skill in cloud detection. However, there are many surface conditions where this characterization of clouds is oversimplified and inappropriate, most notably over snow and sea ice surfaces. Additionally, some cloud types, such as thin cirrus and small cumulus are difficult to detect because of insufficient contrast with the surface radiance (or reflectance). Cloud edges cause further difficulty since the instrument field of view will not always be completely cloudy or clear. The 50-channel MAS offers an opportunity to explore and refine multispectral approaches to cloud detection so that many of these concerns can be diminished considerably.

We begin by describing the approach and algorithms used to detect clouds during daytime conditions in the high Arctic during summer. This represents a subset of all conditions and channels used to process global satellite data using MODIS. Given the results from the cloud mask, we have developed an algorithm, currently implemented in the MODIS global processing system, to estimate the thermodynamic phase of clouds (Platnick et al. 2003). Finally, we have retrieved the cloud optical thickness and effective radius for the "cloudy" scenes identified from the MAS during FIRE ACE. Results obtained from the ER-2 on 4 June 1998 during FIRE $\mathrm{ACE}$ are presented to illustrate the results of applying these cloud tests, thermodynamic phase decisions, and cloud microphysical retrievals to a wide range of conditions. We compare two different algorithms for de- termining cloud optical and microphysical properties of both liquid water and ice clouds over snow and sea ice surfaces. Comparison of these results helps to assess the accuracy that can be expected from global analysis of cloud optical properties from MODIS over polar regions during the daytime.

\section{Instrumentation}

The MAS is a cross-track scanning spectrometer that measures reflected solar and emitted thermal radiation in 50 narrowband channels. For the FIRE ACE deployment, the configuration of the MAS contained channels between 0.47 and $14.0 \mu \mathrm{m}$. Flown aboard the NASA ER-2 aircraft, the MAS is a cross-track scanner with the maximum scan angle extending $43^{\circ}$ on either side of nadir ( $86^{\circ}$ full-swath aperture). At a nominal ER-2 altitude of $20 \mathrm{~km}$, this yields a swath width of $37.2 \mathrm{~km}$ at the earth's surface, centered on the aircraft ground track, with a total of 716 earth-viewing pixels acquired per scan. With each pixel having a 2.5 -mrad instantaneous field of view, the spatial resolution is $50 \mathrm{~m}$ at nadir from the nominal aircraft altitude.

Table 1 summarizes the band center and bandwidth characteristics as well as the main purpose of each MAS band during FIRE ACE. Some of these bands are used to discriminate clouds from clear sky (cloud mask) where others are used to derive the optical and microphysical properties of clouds. The bands used for these purposes are identified in Table 1, and a detailed description of the algorithms will be presented in section 3. Radiometric calibration of the shortwave $(<2.5 \mu \mathrm{m})$ channels was obtained by observing laboratory standard integrating sphere sources on the ground before and after this experiment, while calibration of the infrared channels was performed by viewing two onboard blackbody sources once every scan. A detailed description of the optical, mechanical, electronics, and data acquisition system design of the MAS can be found in King et al. (1996).

\section{Cloud retrievals}

In order to derive cloud optical and microphysical properties, either from high-altitude remote sensing aircraft (NASA ER-2) or from satellites (Terra or Aqua), it is necessary to perform the following steps: 1) identify the probability of a given pixel being cloud contaminated, 2) determine the likely phase of the cloud to be analyzed, and 3) derive the cloud optical and microphysical properties (such as optical thickness, effective radius, cloud-top altitude, etc.). In this section we will describe each of these steps in turn, focusing on specific characteristics of the cloud retrieval process that are important considerations for clouds overlying snow and sea ice surfaces during summer, daytime conditions. 
TABLE 1. Spectral and radiometric characteristics of all MAS bands used in the cloud mask and cloud optical property retrievals during FIRE ACE (daytime conditions).

\begin{tabular}{|c|c|c|c|c|c|c|}
\hline $\begin{array}{l}\text { MAS } \\
\text { band }\end{array}$ & $\begin{array}{c}\text { Equivalent } \\
\text { MODIS } \\
\text { band }\end{array}$ & $\begin{array}{c}\text { Central } \\
\text { wavelength } \\
(\mu \mathrm{m})\end{array}$ & $\begin{array}{l}\text { Spectral } \\
\text { resolution } \\
(\mu \mathrm{m})\end{array}$ & $\begin{array}{l}\text { Cloud } \\
\text { mask }\end{array}$ & $\begin{array}{l}\text { Cloud } \\
\text { retrievals }\end{array}$ & Primary purpose(s) \\
\hline 3 & 1 & 0.66 & 0.05 & $\sqrt{ }$ & $\sqrt{ }$ & $\begin{array}{l}\text { Low thick cloud, shadow; cloud opti- } \\
\text { cal thickness over land }\end{array}$ \\
\hline 7 & 2 & 0.87 & 0.04 & $\sqrt{ }$ & $\sqrt{ }$ & $\begin{array}{l}\text { Low thick cloud, shadow; cloud opti- } \\
\text { cal thickness over ocean }\end{array}$ \\
\hline 10 & 6 & 1.62 & 0.05 & & $\sqrt{ }$ & $\begin{array}{l}\text { Cloud opical thicknss over snow and } \\
\text { sea ice }\end{array}$ \\
\hline 15 & & 1.88 & 0.05 & $\sqrt{ }$ & & Thin cirrus \\
\hline 20 & 7 & 2.13 & 0.05 & & $\sqrt{ }$ & Cloud effective radius \\
\hline 31 & 21 & 3.92 & 0.16 & $\sqrt{ }$ & & Fog, low cloud \\
\hline 42 & 29 & 8.38 & 0.47 & $\sqrt{ }$ & & Thin cirrus and low clouds \\
\hline 45 & 31 & 10.71 & 0.54 & $\sqrt{ }$ & & Cirrus and low clouds \\
\hline 46 & 32 & 11.67 & 0.56 & $\sqrt{ }$ & & Midlevel cirrus \\
\hline 50 & 35 & 13.98 & 0.53 & $\sqrt{ }$ & & High cloud \\
\hline
\end{tabular}

\section{a. Cloud mask}

The cloud mask algorithm determines whether a given view of the earth surface is unobstructed by clouds or optically thick aerosol, and whether a clear scene is contaminated by shadow. The algorithm is divided into 10 conceptual domains according to surface type (land, ocean, snow/ice, coastal, and desert) and solar illumination (daytime and nighttime). In this paper, for application to MAS data over the high Arctic during northern summer, we are concerned only with daytime conditions, where daytime is defined for solar zenith angles $\theta_{0}<85^{\circ}$. The United States Geological Survey $1-\mathrm{km}$ land-sea tag file is used for land-water discrimination. Over land, ecosystem classification is based on the 1km International Geosphere-Biosphere Programme (IGBP) land cover dataset consisting of 17 land cover classes (Loveland and Belward 1997), and is supplemented by an automatic snow classification within the cloud mask algorithm for clear skies. Under conditions of cloudy skies and/or polar regions containing sea ice, this surface classification is supplemented by the National Snow and Ice Data Center (NSIDC) near-realtime ice and snow extent (NISE) dataset that is available daily at $25-\mathrm{km}$ resolution and is based on satellite-borne microwave radiometers using an algorithm described by Armstrong and Brodzik (2002).

The threshold between a pixel being classified as cloudy or clear is sometimes ambiguous due to instrument noise and natural variability. To allow for imprecise measurements of the real world and to accommodate a wide variety of applications, the cloud mask is more than a simple yes-no decision. The cloud mask includes four levels of "confidence" with regard to whether a pixel is classified as clear (cf. Ackerman et al. 1998; King et al. 1998, 2003). Confidence flags convey the strength of conviction in the outcome of the cloud mask algorithm tests for a given field of view (FOV). A confidence flag for each individual test, based on proximity to a threshold value, is assigned and used to derive a final quality flag determination for the pixel. The current scheme applies a linear interpolation between a low-confidence clear (confidence $=0$ ) and highconfidence clear (confidence $=1$ ) threshold for each spectral test. The final determination is a combination of the confidence indices of all applied tests.

The confidence levels of each spectral test must be combined to determine the final decision on whether a pixel is classified as clear or cloudy. Since several of the spectral tests are not independent of one another, the cloud mask algorithm first groups individual spectral tests. The MAS has many channels that are similar to or comparable to those in MODIS, but it lacks a few channels that are important in the MODIS cloud mask. On MAS, the band at $1.88 \mu \mathrm{m}$ is in a strong water vapor absorption band and is, therefore, quite comparable to the 1.38- $\mu \mathrm{m}$ band on MODIS. Both of these bands serve a similar purpose of aiding in the identification of subvisible, high-altitude cirrus clouds. MAS also lacks any bands in the $6.7-\mu \mathrm{m}$ water vapor region, a band that appears to be quite important in identifying water versus ice clouds (see below). Due to a lack of any band in the 6.7- $\mu \mathrm{m}$ region, MAS performs its cloud mask spectral tests in four (rather than five) groups: 1) detecting thick high clouds with thermal infrared thresholds, 2) detecting thin high clouds with brightness temperature difference tests, 3 ) detecting low clouds using solar reflectance tests, and 4) detecting upper-tropospheric thin clouds using near-infrared $(1.88 \mu \mathrm{m})$ thresholds. Table 2 lists the MAS spectral tests that have been performed for all daytime conditions and for all five ecosystems. Thresholds for each group can be found in the MODIS cloud mask Algorithm Theoretical Basis Document (Ackerman et al. 2002).

As described by Ackerman et al. (1998) and King et al. (1998), a minimum confidence is determined for each group as follows:

$$
G_{j=1, N}=\min \left(F_{i j}\right)_{i=1, m},
$$


TABLE 2. MAS cloud mask spectral tests executed $(\sqrt{ })$ for a given processing path.

\begin{tabular}{|c|c|c|c|c|c|c|}
\hline \multirow[b]{2}{*}{ Group } & \multirow[b]{2}{*}{ Test } & \multicolumn{5}{|c|}{ MAS daytime cloud mask test layout for a given processing path } \\
\hline & & Ocean & Land & Snow/ice & Coastline & Desert \\
\hline \multicolumn{7}{|c|}{ Infrared threshold } \\
\hline I & $T_{10.7}$ & $\sqrt{ }$ & & & & \\
\hline I & $T_{14}$ & $\sqrt{ }$ & $\sqrt{ }$ & $\sqrt{ }$ & $\sqrt{ }$ & $\sqrt{ }$ \\
\hline \multicolumn{7}{|c|}{ Brightness temperature difference } \\
\hline II & $T_{8.4}-T_{10.7}$ & $\sqrt{ }$ & & & & \\
\hline II & $T_{10.7}-T_{11.7}$ & $\sqrt{ }$ & $\sqrt{ }$ & & $\sqrt{ }$ & $\sqrt{ }$ \\
\hline II & $T_{10.7}-T_{3.9}$ & $\sqrt{ }$ & $\sqrt{ }$ & $\sqrt{ }$ & $\sqrt{ }$ & $\checkmark$ \\
\hline \multicolumn{7}{|c|}{ Solar reflectance tests } \\
\hline III & $R_{0.66}$ & & $\checkmark$ & & $\checkmark$ & \\
\hline III & $R_{0.87}$ & $\sqrt{ }$ & & & & $\sqrt{ }$ \\
\hline III & $R_{0.87} / R_{0.66}$ & $\sqrt{ }$ & $\sqrt{ }$ & & & $\checkmark$ \\
\hline \multicolumn{7}{|c|}{ Near-infrared threshold } \\
\hline IV & $R_{1.88}$ & $\checkmark$ & $\checkmark$ & $\sqrt{ }$ & $\checkmark$ & $\checkmark$ \\
\hline
\end{tabular}

where $F_{i}$ is the confidence level of an individual spectral test, $m$ is the number of tests in a given group, and $N$ is the number of groups (four in this case). The overall cloud mask result $(Q)$ is then determined from the product of the results from each group:

$$
Q=\sqrt[N]{\prod_{j=1}^{N} G_{j}} .
$$

This approach is clear-sky conservative in the sense that if any test is highly confident that the scene is cloudy $\left(F_{i}=0\right)$, the final clear-sky confidence is 0 . The result of this cloud mask test, together with processing path flags, heavy aerosol and shadow flags, and results from individual spectral and spatial tests, is stored in the 48bit cloud mask file for each pixel (cf. Ackerman et al. 1998). In this paper these two-bit cloud mask results will be interpreted as follows: 1) confident clear $(Q>$ $0.99), 2)$ probably clear $(Q>0.95), 3)$ probably cloudy $(Q>0.66)$, and 4$)$ cloudy $(Q \leq 0.66)$.

\section{b. Thermodynamic phase}

Once the cloud mask has been run for all pixels in a scene, it is necessary to interpret the results for application of the cloud retrieval code that follows (see below). Figure 1 shows the flowchart for determining the presence of clouds during the daytime using results reported in the cloud mask. Bit 0 of the cloud mask indicates whether a cloud mask result has been obtained for a given pixel, and if so, we check whether the pixel was observed during daytime or nighttime conditions. Next, we read the ecosystem classification bits in the cloud mask to determine which of the five ecosystems the pixel was acquired over. Since the ecosystem dataset applies to the static ecosystem of land versus water, supplemented by a dynamic snow index for clear-sky pixels, it does not, at this point, incorporate the dynamics of surface snow and sea ice that vary on a daily basis when the pixel is cloud covered. As this is of particular interest for our subsequent cloud retrievals, we supplemented this ecosystem map with the NISE ancillary dataset to determine whether snow or sea ice occurs beneath the potentially cloudy pixel.

Figure 2 shows the cloud mask tests that are run for pixels over snow and sea ice surfaces to determine whether the pixel contains clear sky, water cloud, ice cloud, or clouds of undetermined phase. If the scene is classified as cloudy or probably cloudy, then the tests available over snow and sea ice surfaces (cf. Table 2) are run individually to estimate the thermodynamic phase of the clouds in the scene. As there are limited tests available from the cloud mask, and the thresholds are set globally based on tests using MODIS data, it is possible that ambiguous phase identification still results from these cloud mask results. During the FIRE ACE experiment, all five ecosystems were encountered by the ER-2. Cloud mask tests for phase determination for each of these ecosystems, including the snow/ice ecosystem, can be found online (modis-atmos.gsfc.nasa.gov/ MOD06_L2/MAS_Cloud_Mask_Tests.pdf).

Following the cloud mask tests, we run a number of additional tests aimed at increasing the confidence in the cloud thermodynamic phase and reducing the potentially large number of undetermined phase determinations (cf. Fig. 3). The first such test is a bispectral threshold algorithm based on the brightness temperature difference between 8.4 and $10.7 \mu \mathrm{m}$. This is a simplified and robust modification of the trispectral phase algorithm first described by Strabala et al. (1994), which in turn is based on the difference in the optical properties between water droplets and ice crystals, as described by Baum et al. (2000b). This test is run only for those cloudy pixels for which the cloud mask tests led to an undetermined phase. The bispectral threshold algorithm can be summarized as follows: an ice cloud is identified when $T_{10.7} \leq 238 \mathrm{~K}$ or $T_{8.4}-T_{10.7} \geq 0.5 \mathrm{~K}$, a water cloud is identified when $T_{10.7}>285 \mathrm{~K}$ and $T_{8.4}-T_{10.7}$ 


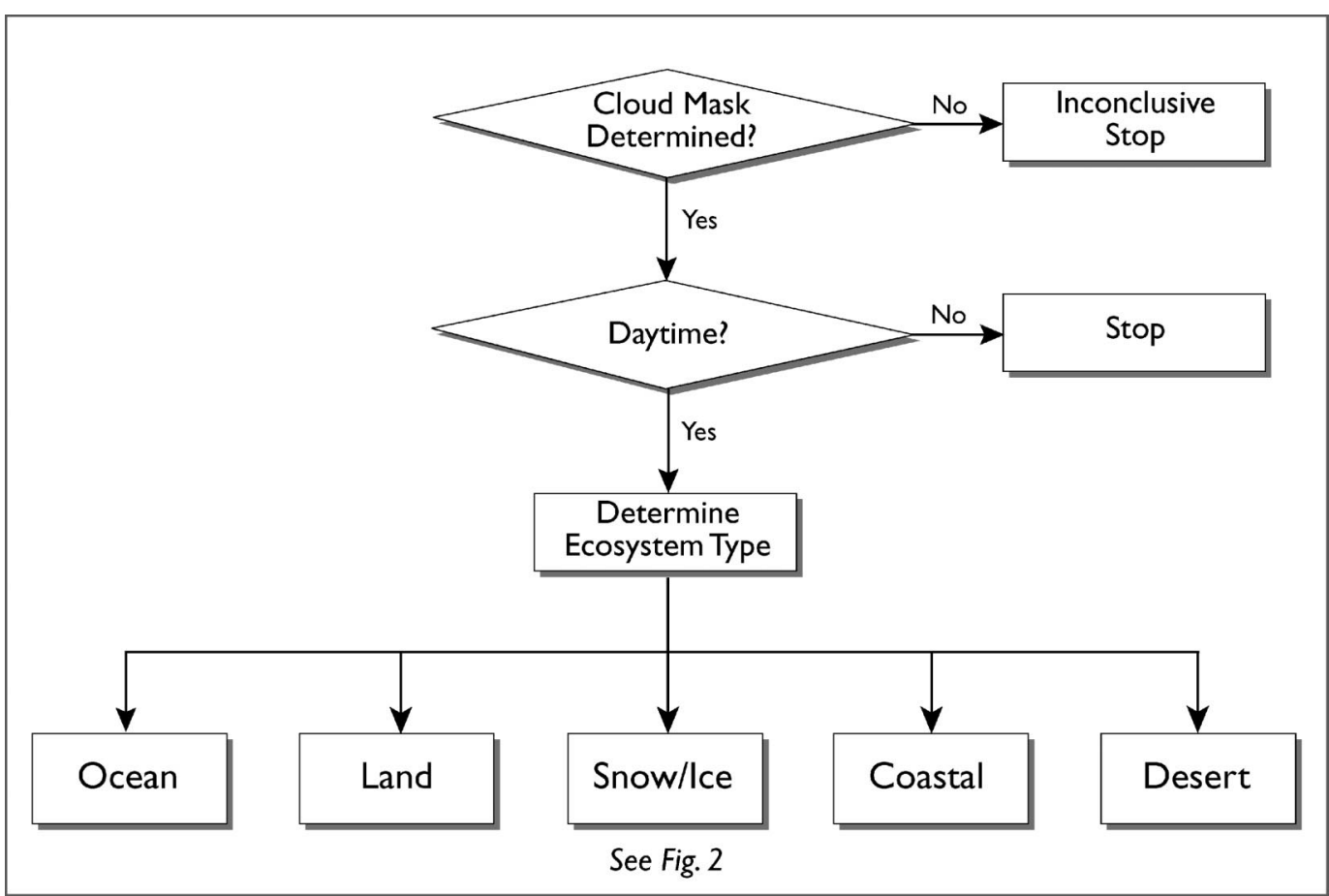

FIG. 1. Flowchart for determining the presence of clouds during the daytime from the MAS cloud mask.

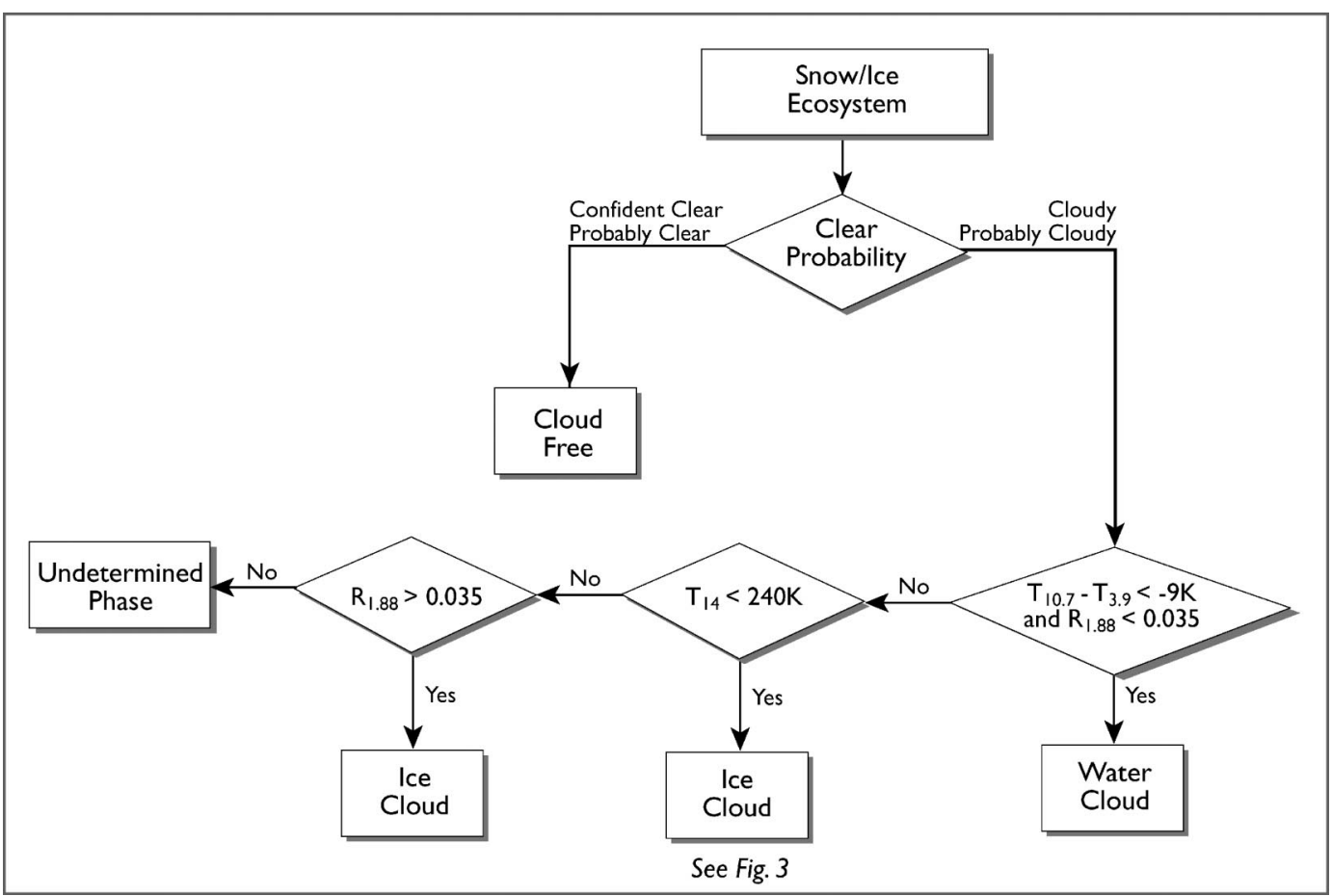

FIG. 2. Cloud mask tests for an initial determination of the presence of water clouds, ice clouds, and clear sky over snow and sea ice surfaces during the daytime. 


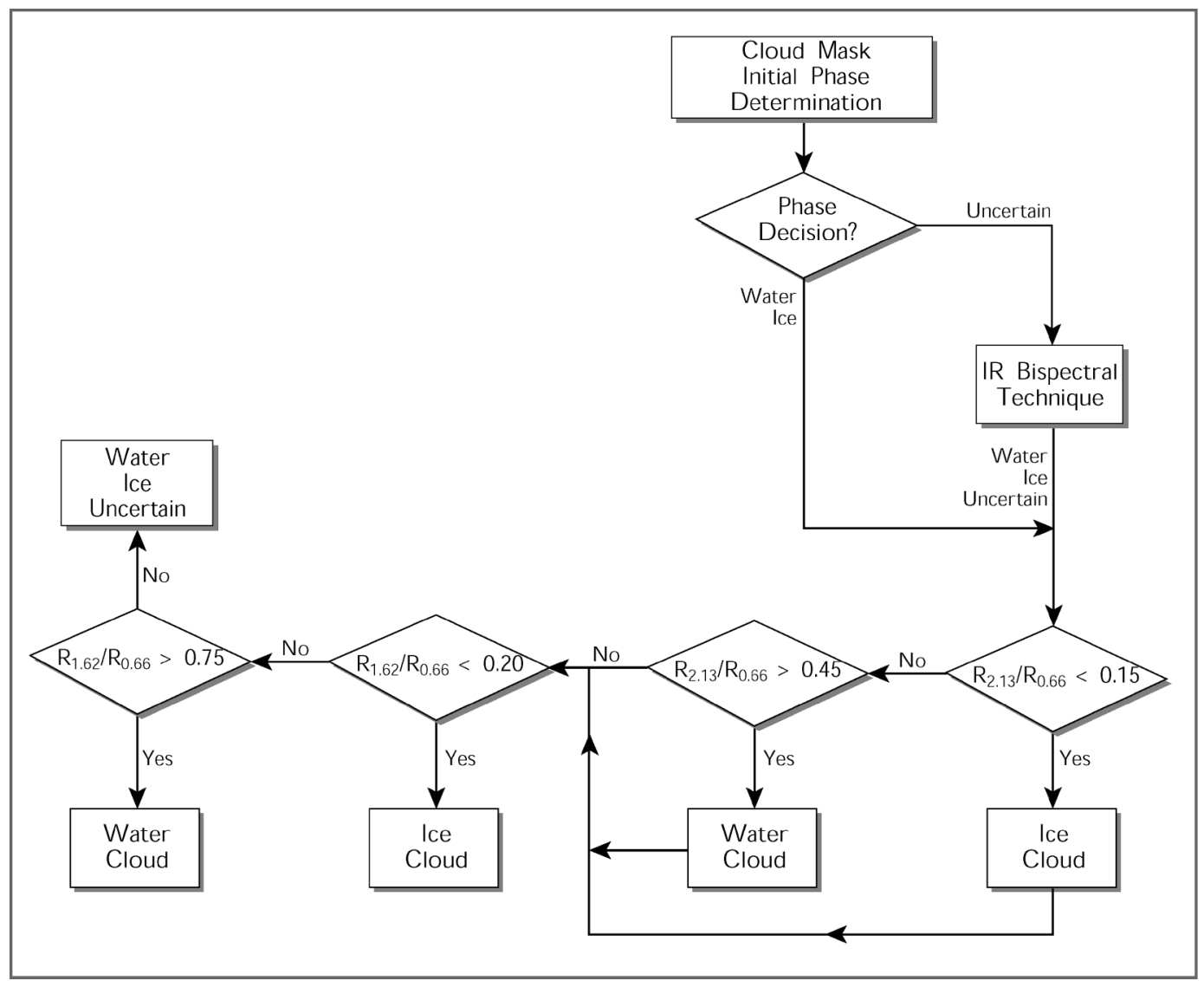

FIG. 3. Flowchart for determining the final thermodynamic phase of clouds during the daytime over snow and sea ice surfaces

$\leq-0.5 \mathrm{~K}$ or $T_{10.7}>238 \mathrm{~K}$ and $T_{8.4}-T_{10.7} \leq-1.0 \mathrm{~K}$, and a mixed phase cloud is identified if $238 \mathrm{~K}<T_{10.7}$ $<268 \mathrm{~K}$ and $-0.25 \mathrm{~K} \leq T_{8.4}-T_{10.7}<0.5 \mathrm{~K}$; otherwise an uncertain cloud classification is retained.

Following this test, all cloudy pixels are subjected to additional tests of the reflectance ratio between the shortwave infrared bands at 2.1 and $1.6 \mu \mathrm{m}$ and a visible, nonabsorbing band at $0.66 \mu \mathrm{m}$. The threshold values used over snow and sea ice surfaces are shown in Fig. 3. For all other ecosystems, these threshold values are somewhat different and can be found online (modisatmos.gsfc.nasa.gov/MOD06_L2/MAS_Final_Phase. pdf).

In all significant ways, this is the same algorithm that is applied to determine the thermodynamic phase of clouds using MODIS data from the Terra and Aqua spacecraft, except that the 1.6- $\mu \mathrm{m}$ shortwave infrared tests are not applied on the Aqua/MODIS instrument due to detector failures on this instrument. In addition, for MODIS we implement additional cloud-top temperature "sanity checks" not implemented in MAS processing. These tests ensure that any cloud whose cloudtop temperature is warmer (colder) than $273 \mathrm{~K}(233 \mathrm{~K})$ is liquid water (ice).

\section{c. Optical properties of liquid water and ice clouds}

After the cloud mask and thermodynamic phase estimation has been performed, the physical and optical properties of ice clouds can, in principle, be retrieved in a manner similar to that for liquid water clouds, outlined below. The vertical scales of cirrus clouds are normally much smaller than their horizontal scales. Thus, it is expected that the three-dimensional effect for cirrus clouds is relatively insignificant, as compared to the case for broken water clouds such as cumulus clouds. In the generation of the forward lookup library for cirrus reflectance, the commonly used plane-parallel atmosphere is assumed. Under this assumption, two other factors complicate the retrievals of ice cloud properties (viz., the shape and orientation of ice crystals) that occur naturally in the atmosphere. Due to our limited knowledge accumulated thus far for ice clouds, the sensitivity of their retrieved properties on these two factors is still an ongoing area of current research. In the present study, ice crystals are assumed to be randomly oriented in space, and the corresponding phase functions for ice clouds are functions of scattering angle. Note that phase functions for ice crystals with specific orientations de- 
pend on the scattering angle as well as the azimuth angle of the scattering plane to which the phase function is referenced. For ice crystal shapes, we use the percentage of each habit derived from statistics based on in situ observations.

We have carried out single-scattering calculations for ice crystals with different sizes and shapes. The sizes (measured along the maximum dimension of the crystals) range from 10 to $800 \mu \mathrm{m}$, while the shapes vary from bullet rosettes, hollow columns, plates, aggregates to ice crystals with rough surfaces. The single-scattering properties and phase functions at the four MAS bands for which cloud retrievals are performed (cf. Table 1) are presented for 12 size distributions observed for midlatitude cirrus cloud systems, as described by Takano and Liou (1989) and Fu (1996). The single-scattering calculations were carried out using the combination of the improved geometric optics method (GOM2; Yang and Liou 1996b) and the finite-difference time domain (FDTD) technique (Yang and Liou 1996a). FDTD is applied to size parameters smaller than 20 whereas GOM2 is employed for size parameters larger than 20.

Following Takano and Liou (1989), we discretized the size distributions using five size bins: 10-30 $\mu \mathrm{m}$ with bin center at $20 \mu \mathrm{m}, 30-70 \mu \mathrm{m}$ with bin center at $50 \mu \mathrm{m}, 70-170 \mu \mathrm{m}$ with bin center at $120 \mu \mathrm{m}, 170-$ $430 \mu \mathrm{m}$ with bin center at $300 \mu \mathrm{m}$, and $430-1070 \mu \mathrm{m}$ with bin center at $750 \mu \mathrm{m}$. The discretized number con- centration of ice crystals is depicted in Fig. 4 with respect to the maximum dimension of the ice crystals. Nasiri et al. (2002) investigated the effect of bin resolution of the discretized size distribution and found that a finer bin resolution can modify calculated reflectances for the near-infrared bands where the absorption of ice is considerable. However, with relevance to the inversion problem, we find that the effective size of the finerresolution distribution also changes such that the reflectance properties as a function of effective size undergo little change. The effective size for a given size distribution is defined as follows:

$$
D_{e}=\frac{3}{2} \frac{\int \operatorname{Vn}(D) d D}{\int \operatorname{An}(D) d D}=\frac{3}{2} \frac{\mathrm{IWC} / \rho_{\text {ice }}}{\bar{A} N_{\text {ice }}}
$$

where $D, V$, and $A$ denote the maximum dimension, volume, and projected area of the ice crystals, respectively; $\bar{A}$ is the mean projected area; $N_{\text {ice }}$ is the total number concentration of ice crystals; IWC is the ice water content; and $\rho_{\text {ice }}$ is the bulk density of ice $(0.92$ $\left.\mathrm{g} \mathrm{cm}^{-3}\right)$. The preceding definition of effective size is applicable to irregular and complex ice crystal shapes, and does not require that the crystals be hexagonal columns. In addition, this definition of effective size is
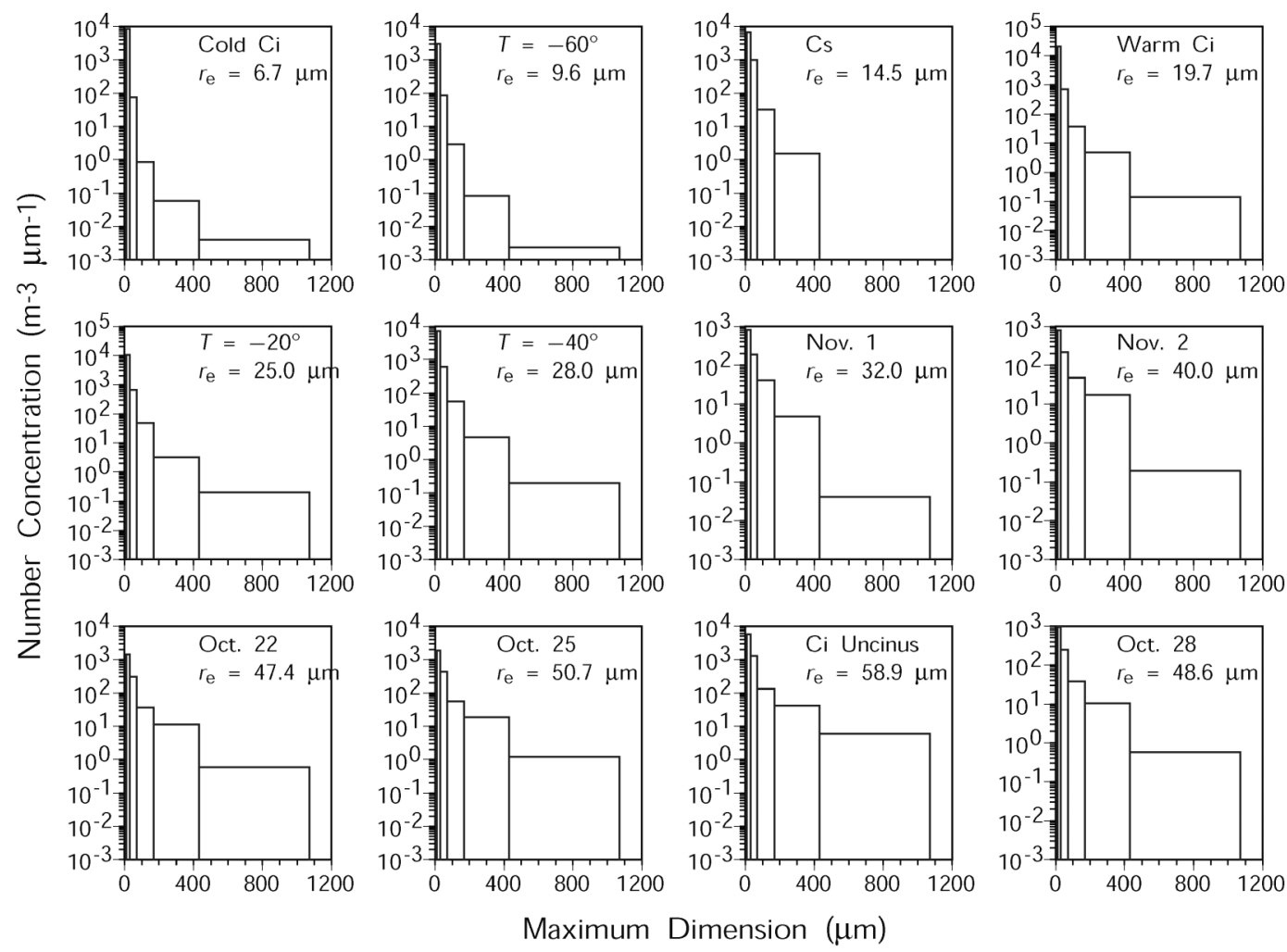

FIG. 4. Ice crystal size distributions for midlatitude cirrus cloud systems. 
(a) Ice crystal shapes frequently observed in cirrus clouds
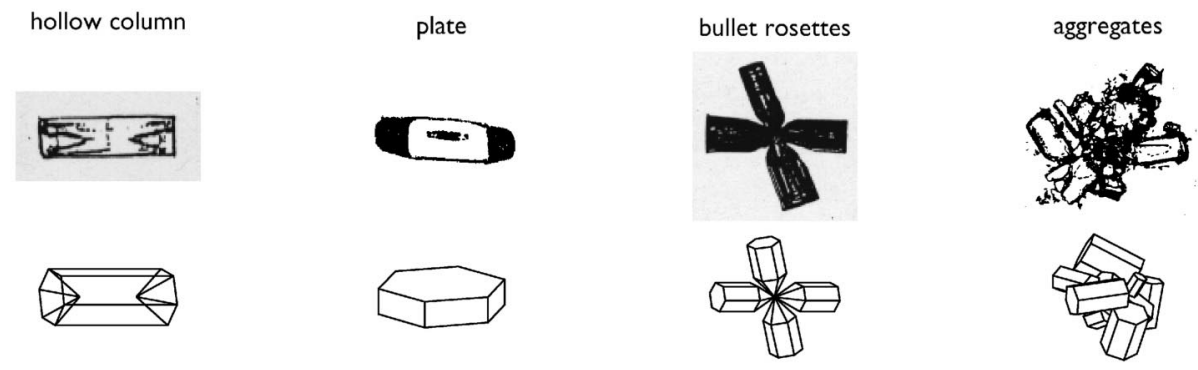

(b) MODIS/MAS cirrus cloud microphysical model

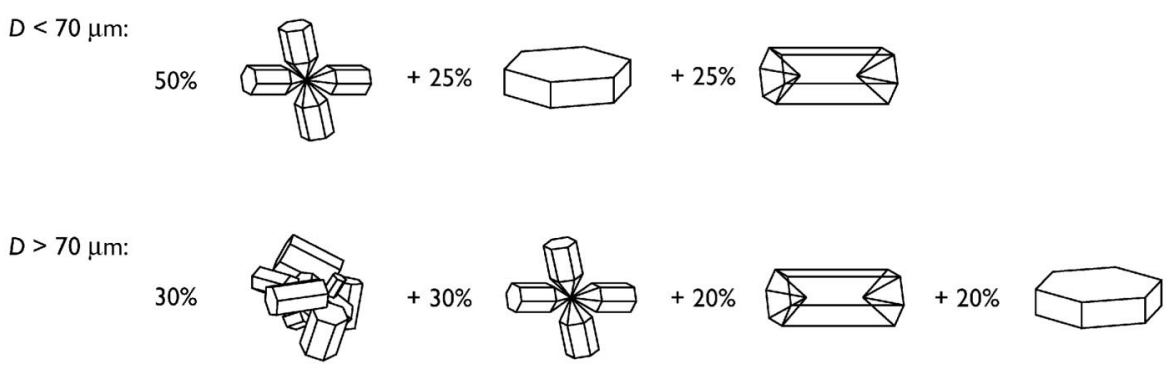

FIG. 5. (a) The ice crystal shapes commonly observed in cirrus clouds. (b) The microphysical model in terms of habit percentage that is used for MODIS/MAS retrievals of cirrus clouds. Note that $D$ is the maximum dimension of an ice crystal.

directly related to IWC and crystal projected area, which can be measured using a two-dimensional optical cloud probe.

There are many ways to define effective particle size for a distribution of particles. Wyser and Yang (1998) showed that the optical properties of ice crystals are insensitive to the detailed shape of the size distribution if the effective size is defined by Eq. (3). A recent study by Mitchell (2002) also shows the advantage of the effective size as defined by Eq. (3). Finally, it can been shown that the present definition of effective size is a generalization of the effective radius defined by Hansen and Travis (1974) and given by

$$
r_{e}=\frac{\int_{0}^{\infty} r^{3} n(r) d r}{\int_{0}^{\infty} r^{2} n(r) d r},
$$

where $n(r)$ is the particle size distribution and $r$ is the particle radius. This is the definition we have applied to our water cloud retrievals. In order to be consistent, we have computed the effective radius of the 12 ice crystal models using Eq. (3) and dividing the resulting $D_{e}$ by 2 . These values are contained within the individual panels of Fig. 4.

At this point, sufficient information concerning ice crystal habit and percentage of individual habit for a given size distribution is not available. In this investi- gation, as well as in the processing of MODIS data, we assumed ice crystal habits and corresponding percentages for a model cirrus cloud based primarily on replicator data collected during the FIRE-II intensive field observation (IFO). Figure 5 illustrates four shapes that we have numerically defined for single-scattering calculations, where observed in situ ice crystal shapes are also presented for comparison. The percentage of each habit that we assumed in our calculations varies with particle size. For small ice crystals $(D<70 \mu \mathrm{m})$, we assumed the particle shapes are relatively simple, and characterized as $50 \%$ bullet rosettes, $25 \%$ hollow columns, and $25 \%$ plates. For large particles, we assume that bullet rosettes and aggregates dominate the particle size distribution, where the particles are composed of $30 \%$ aggregates, $30 \%$ bullet rosettes, $20 \%$ hollow columns, and $20 \%$ plates. The ice crystal habit percentages used in this investigation have also be used in remote sensing applications by Baum et al. (2000a) and in the parameterization of the radiative properties of ice clouds (e.g., Chou et al. 2002). The aspect ratio or dimensional relationship used in the calculations is taken from Auer and Veal (1970), and more recently examined by Korolev and Isaac (2003), who obtained in situ measurements in winter midlatitude and polar stratiform ice clouds using a cloud particle imager (CPI) at $2.3-\mu \mathrm{m}$ resolution. For aggregates, the effect of crystal surface roughness is accounted for in the calculations, with the magnitude mathematically defined by using the Gram- 
TABLE 3. Real and imaginary parts of the complex refractive index of liquid water and ice clouds for four MAS bands used in cloud optical property retrievals during FIRE ACE.

\begin{tabular}{|c|c|c|c|c|c|c|c|}
\hline \multirow{2}{*}{$\begin{array}{l}\text { MAS } \\
\text { band }\end{array}$} & \multirow{2}{*}{$\begin{array}{c}\text { Equivalent } \\
\text { MODIS } \\
\text { band }\end{array}$} & \multirow{2}{*}{$\begin{array}{c}\text { Central } \\
\text { wavelength } \\
(\mu \mathrm{m})\end{array}$} & \multirow{2}{*}{$\begin{array}{l}\text { Spectral } \\
\text { resolution } \\
(\mu \mathrm{m})\end{array}$} & \multicolumn{2}{|c|}{ Liquid water } & \multicolumn{2}{|c|}{ Ice } \\
\hline & & & & $m_{r}$ & $m_{i}$ & $m_{r}$ & $m_{i}$ \\
\hline 3 & 1 & 0.66 & 0.05 & 1.331 & $1.865 \times 10^{-8}$ & 1.308 & $1.364 \times 10^{-8}$ \\
\hline 7 & 2 & 0.87 & 0.04 & 1.328 & $3.790 \times 10^{-7}$ & 1.304 & $2.106 \times 10^{-7}$ \\
\hline 10 & 6 & 1.62 & 0.05 & 1.318 & $8.618 \times 10^{-5}$ & 1.288 & $2.529 \times 10^{-4}$ \\
\hline 20 & 7 & 2.13 & 0.05 & 1.297 & $3.920 \times 10^{-4}$ & 1.268 & $6.858 \times 10^{-4}$ \\
\hline
\end{tabular}

Charlier distribution (Cox and Munk 1954). The variation from slight roughness to moderate roughness is randomly selected for each orientation by averaging the effect of particle orientations. For other crystal shapes, a smooth surface geometry is employed in the singlescattering calculations.

In order to assess the impact of finite bandpass characteristics of the MAS on our cloud retrieval algorithm, we performed calculations of the phase function using 11-100 equally spaced wavelengths for each band. These results were then compared with computations based on a single wavelength at the bandpass center. Numerical results show that the differences are negligible if the mean values of the refractive index are used. For our computations, we used the complex refractive indices of ice reported by Gosse et al. (1995) for wavelengths greater than $1.4 \mu \mathrm{m}$, which deviate from data published by Warren (1984) by as much as $60 \%$ at some wavelengths. We use Warren's compilation for wave- lengths below $1.4 \mu \mathrm{m}$. For liquid water clouds, we have chosen to use the optical constants tabulated by Hale and Querry (1973) for bands below $0.872 \mu \mathrm{m}$, Palmer and Williams (1974) for the 1.618- $\mu \mathrm{m}$ band, and Downing and Williams (1975) for the $2.133 \mu \mathrm{m}$ and greater bands. Table 3 shows the refractive index assumed in this paper for computations of both liquid water and ice cloud properties.

Figure 6 illustrates some examples of the phase functions of ice crystals at three of the MAS wavelengths used in retrieving cloud optical properties during FIRE ACE. The right-hand panel of Fig. 6 shows that a pronounced $22^{\circ}$ scattering peak is observed for all three wavelengths ( $\mathrm{Ci}$ uncinus, $r_{e}=58.9 \mu \mathrm{m}$ ). However, the results in the left-hand panel show a strong $22^{\circ}$ halo only for the $0.87-\mu \mathrm{m}$ wavelength $\left(\mathrm{Cs}, r_{e}=14.5 \mu \mathrm{m}\right)$. This is because the $22^{\circ}$ halo is significant only for large size parameters, which are smoothed out in the case of small size parameters due to the ray-spreading effect

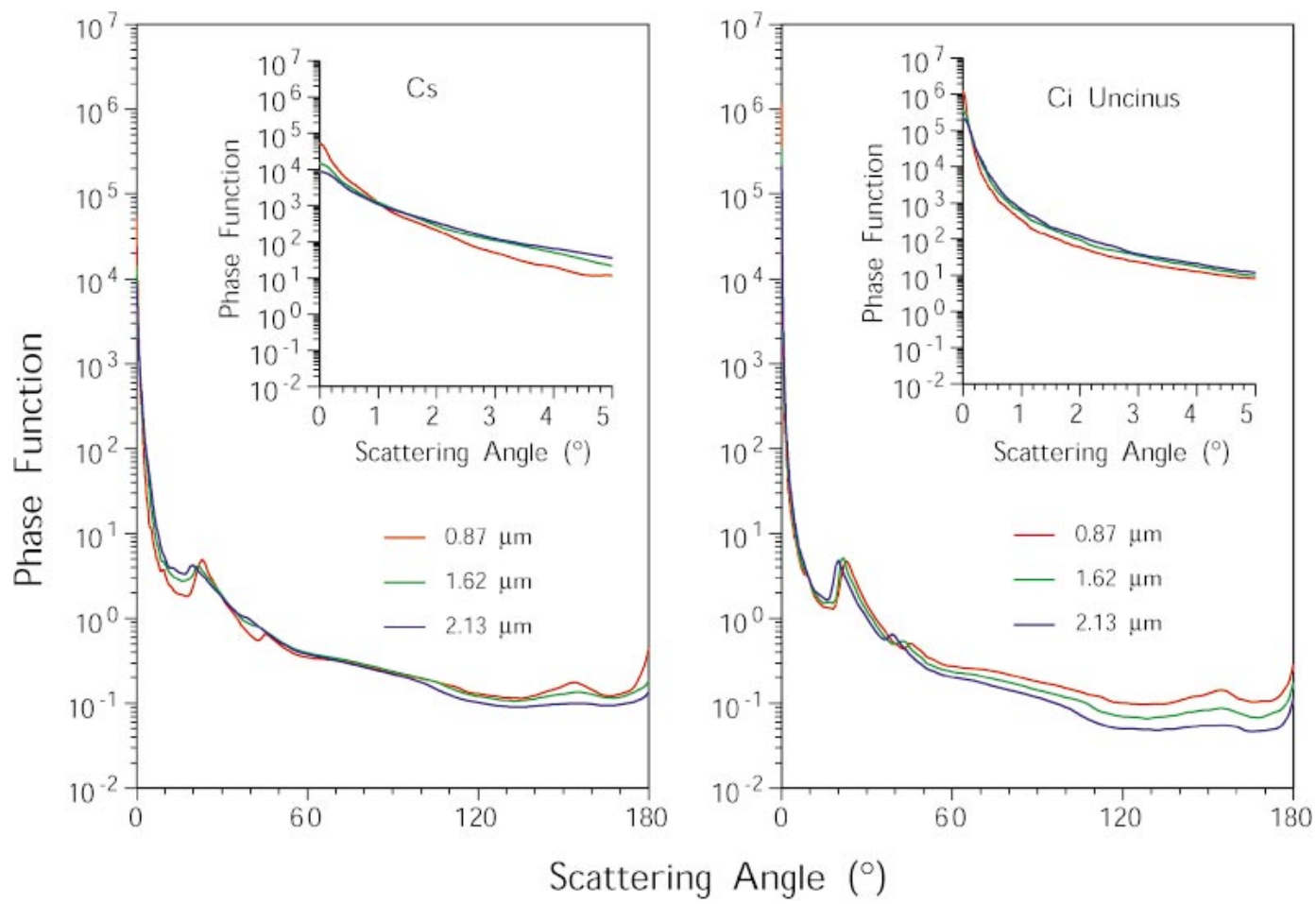

FIG. 6. Phase function computed for MAS bands $7(0.87 \mu \mathrm{m}), 10(1.62 \mu \mathrm{m})$, and $20(2.13 \mu \mathrm{m})$ for the size distributions of $\mathrm{Cs}$ and $\mathrm{Ci}$ uncinus (cf. Fig. 4). 
(Yang and Liou 1996a). The size distribution associated with the cirrostratus model contains many small ice crystals. At 1.62 and $2.13 \mu \mathrm{m}$, the size parameter of these particles is not large enough to produce a pronounced halo peak. At $0.87 \mu \mathrm{m}$, on the other hand, the size parameters of ice crystals are substantially larger, leading to a considerable $22^{\circ}$ scattering peak. For the cirrus uncinus size distribution associated with the righthand panel, there are a substantial number of large ice crystals and the effective radius is therefore much larger. Thus, pronounced halo peaks are observed at all three wavelengths for this case. However, the presence of a halo feature in the phase function is of little or no consequence to MAS reflectance-based retrievals for the solar and viewing geometries encountered.

Phase functions for all 12 ice crystal models and each of the MAS wavelengths have been computed, analogous to those in Fig. 6 for the cirrostratus and cirrus uncinus models. Each of these phase functions is used to generate reflectance properties of the associated cloud in a radiative transfer model. These reflectance libraries are subsequently associated with the effective radius derived from an integration of the size distribution according to Eq. (3) and summarized in each panel of Fig. 4.

\section{d. Retrieval of cloud optical thickness and effective radius}

The simultaneous retrieval of cloud optical thickness and effective radius is best achieved by simultaneously measuring the reflection function at a visible and a nearinfrared wavelength, and comparing the resulting measurements with theoretical calculations, as demonstrated by Nakajima and King (1990). This technique is especially accurate over dark ocean surfaces because the reflection function of the earth-atmosphere system arises primarily from light scattering by the cloud layer, with little influence from the underlying surface. In comparing measurements with theory, however, it is essential that the light-scattering properties of the cloud are modeled realistically, and that the cloud is properly ascribed to either a water cloud or an ice cloud with corresponding optical properties. For applications of this technique to polar regions involving clouds over snow and sea ice surfaces, it is necessary to further assume or otherwise estimate realistic values of the underlying surface reflectance at appropriate visible and near-infrared wavelengths.

Rolland et al. (2000) studied the sensitivity of the remote sensing of cloud optical and microphysical properties using a combination of visible and shortwave infrared bands. They concluded that the single-scattering albedo, asymmetry factor, and phase function of cirrus clouds do not depend greatly on the shape of the size distribution nor its variance; however, overall cloud reflectance does depend greatly on accurate knowledge of surface reflectance. This is especially true for the remote sensing of optically thin clouds (both liquid water and ice) over snow and sea ice surfaces.

Figure 7 illustrates the underlying principles behind the simultaneous determination of cloud optical thickness $\tau_{c}$ and effective radius $r_{e}$ from reflected solar radiation measurements. The minimum value of the reflection function at $2.13 \mu \mathrm{m}$ corresponds to the reflection function of the underlying surface at that wavelength in the absence of an atmosphere. At $0.87 \mu \mathrm{m}$ the reflection function decreases as $\tau_{c}$ increase from 0 to about 2 where it starts to increase. For the computations presented here, we assumed the sea ice present over the Chukchi and Beaufort Seas in May and June was Lambertian with a surface albedo of 0.60 at $0.87 \mu \mathrm{m}$ and 0.03 at $2.13 \mu \mathrm{m}$, agreeing with observations obtained by the Cloud Absorption Radiometer during previous Arctic field campaigns during the melt season (Arnold et al. 2002). The dashed curves in Fig. 7 represent reflection function contours for fixed cloud optical thickness, and the solid curved contours are for fixed effective radius. These results show, as expected, that the reflection function at $0.87 \mu \mathrm{m}$ is largely a function of cloud optical thickness, whereas the reflection function at $2.13 \mu \mathrm{m}$ is largely sensitive to effective radius, with the largest reflectance values corresponding to the smallest particle sizes.

As the Arctic contains both water and ice clouds, we performed model calculations for both liquid water clouds (Fig. 7a) and ice clouds (Fig. 7b) using the refractive index, size distribution, and shape characteristics described in Table 3 and section 3c. The data points superimposed on the theoretical curves of Fig. 7 correspond to MAS observations acquired at the observational solar and viewing directions specified in the figure for 4 June, a day for which the cloud phase algorithm determined the scene in Fig. 7a as a liquid water cloud and the scene in Fig. $7 \mathrm{~b}$ as an ice cloud.

Due to the relatively high surface albedo at $0.87 \mu \mathrm{m}$, we explored an alternative technique for simultaneously retrieving cloud optical thickness and effective radius over snow and sea ice surfaces during FIRE ACE. This method, first described by Platnick et al. (2001), takes advantage of the fact that the surface albedo of snow and sea ice is quite low at $1.62 \mu \mathrm{m}$ (cf. Arnold et al. 2002). Figure 8 illustrates the theoretical relationship and corresponding data points of the simultaneous retrieval of cloud optical thickness and effective radius using measurements at 2.13 and $1.62 \mu \mathrm{m}$, where we assumed the surface albedo of sea ice was 0.03 at both wavelengths. Although one loses the near orthogonality of the retrieval of $\tau_{c}$ and $r_{e}$ using these two channels, and therefore one is more sensitive to calibration uncertainties in the measurements, the sensitivity to effective radius is much better because there is far less uncertainty in the value of the surface albedo. This technique is noticeably more robust for liquid water clouds (Fig. 8a) than for ice clouds (Fig. 8b). 
(a)

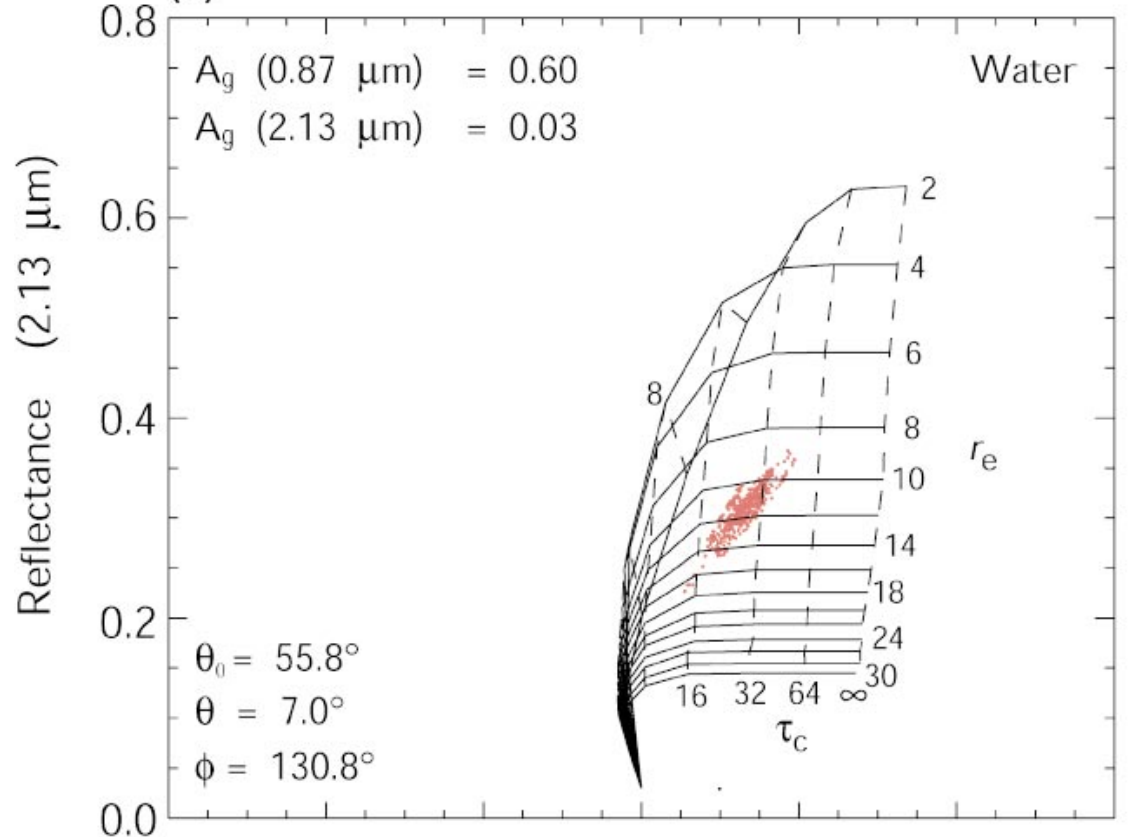

(b)

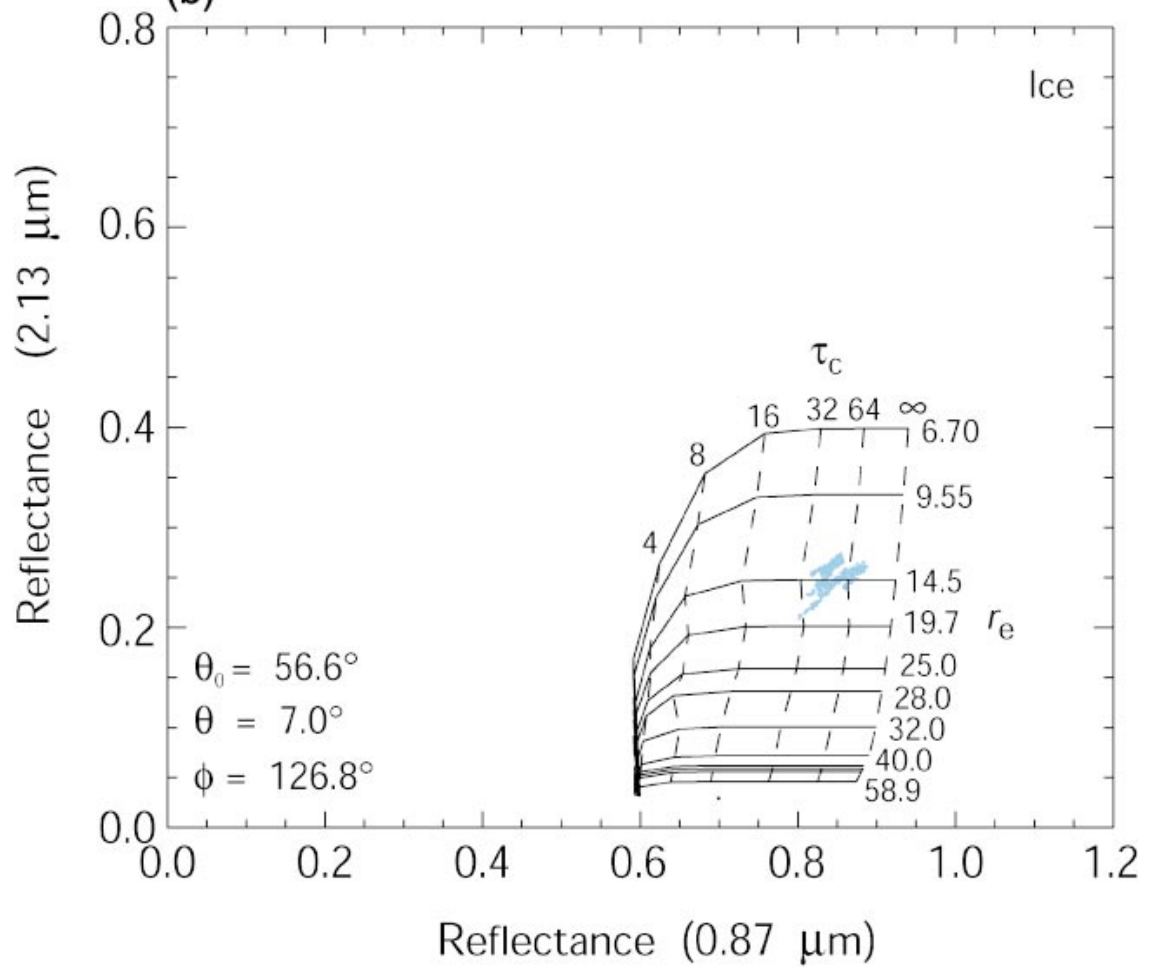

FIG. 7. Theoretical relationship between the reflection function at 0.87 and $2.13 \mu \mathrm{m}$ for (a) water clouds and (b) ice clouds for various values of $\tau_{c}$ (dashed lines) and $r_{e}$ (solid lines) for specified values of surface albedo and $\theta_{0}, \theta$, and $\phi$. Data from measurements above Arctic water and ice clouds are superimposed in the figure. 
(a)

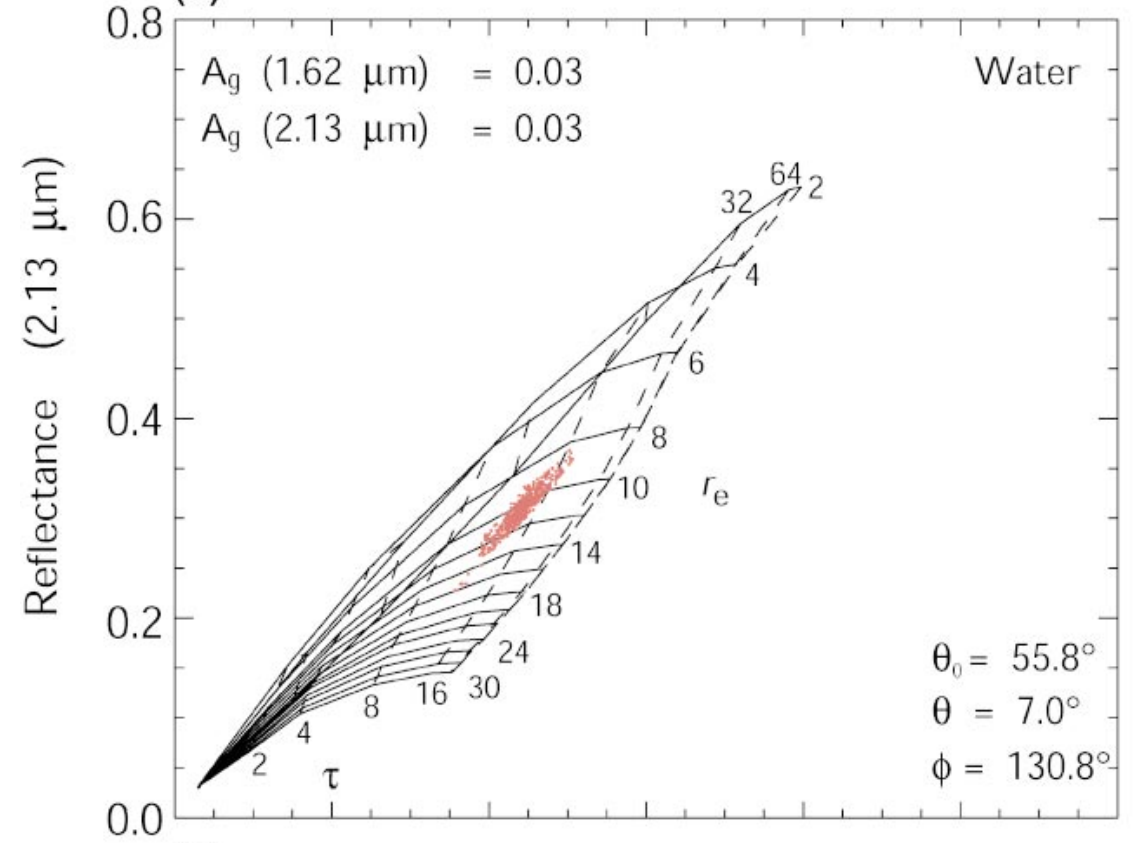

(b)

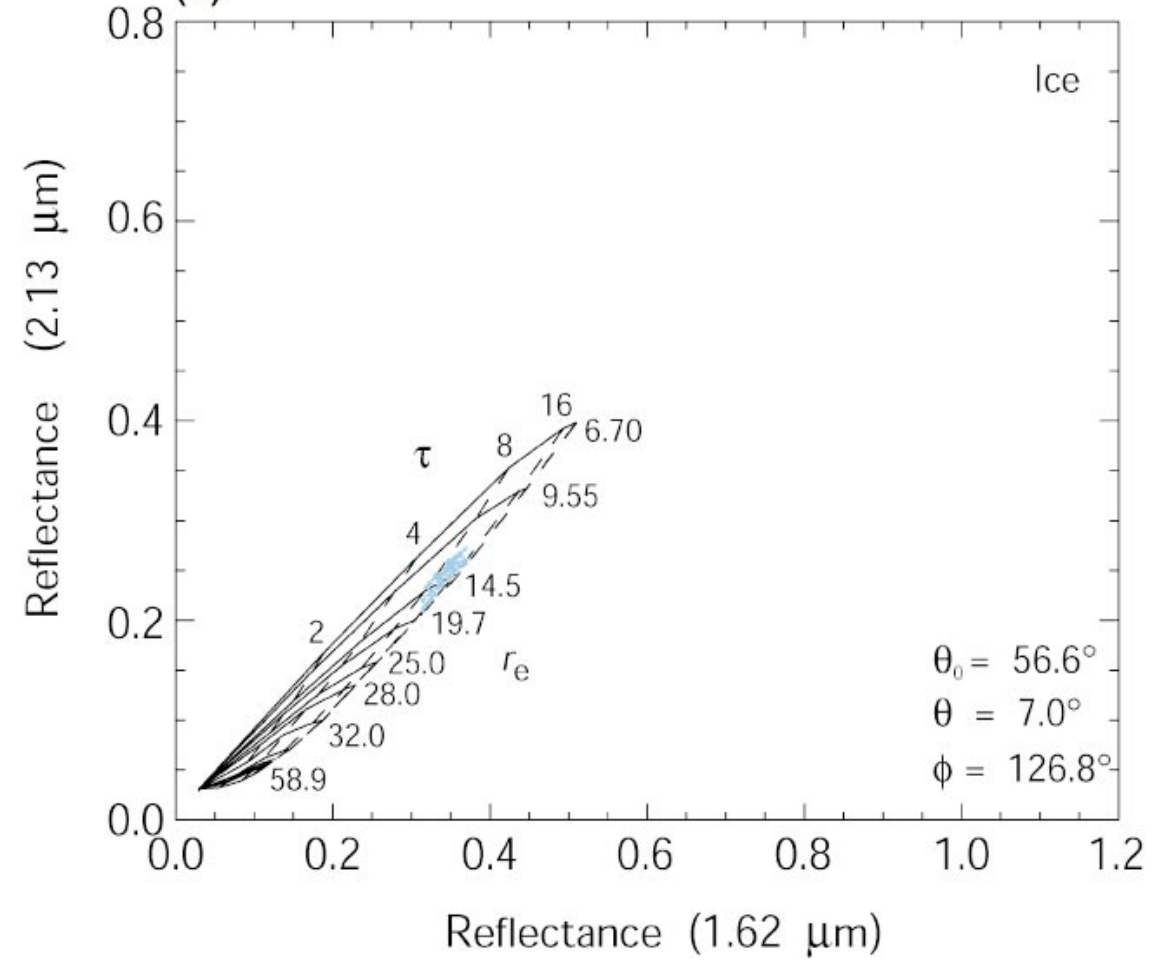

FIG. 8. Theoretical relationship between the reflection function at 1.63 and $2.13 \mu \mathrm{m}$ for (a) water clouds and (b) ice clouds for various values of $\tau_{c}$ (dashed lines) and $r_{e}$ (solid lines) for specified values of surface albedo and $\theta_{0}, \theta$, and $\phi$. Data from measurements above Arctic water and ice clouds are superimposed in the figure. 


\section{Results from observations}

During FIRE ACE, the ER-2 acquired $62.25 \mathrm{~h}$ of data during 11 research flights between 18 May and 6 June 1998. These missions included repeated measurements over ground-based radiometers, lidars, and radars at the SHEBA ice camp (8 flights) and the ARM site in Barrow (11 flights) (Curry et al. 2000). In what follows, we will describe results obtained from the ER-2 on one of these flights, demonstrating the performance of the cloud mask, thermodynamic phase algorithm, and subsequently cloud optical property retrievals over sea ice surfaces during the day.

\section{a. Cloud mask and thermodynamic phase}

On 4 June, the ER-2 overflew the ARM site and then headed northwest toward the SHEBA ice camp to overfly cirrus being advected over the region from the northwest. It then flew four parallel north-south flight legs of approximately $280 \mathrm{~km}$ in length, offset by $40 \mathrm{~km}$, starting from an area east of the ice camp and ending over the station $\left(76^{\circ} 51^{\prime} \mathrm{N}, 167^{\circ} 30^{\prime} \mathrm{W}\right)$. This flight was useful for cloud remote sensing and cloud mask validation, as well as sea ice retrievals in the presence of changing cloud cover. Following the primary observations in the vicinity of the SHEBA ice camp, the ER2 overflew the ARM site on its return leg over the Chukchi Sea, which was aligned with the ground track of the National Oceanic and Atmospheric Administration-14 (NOAA-14) polar-orbiting satellite. The ER-2 pilot reported solid cloud cover throughout most of the mission, with clear sky observed only over the tundra between the Brooks Range and the Arctic Ocean coastline. Figure 9 illustrates the ER-2 ground track for this mission.

Figure 10 shows images of Arctic stratus and altocumulus clouds $205 \mathrm{~km}$ in length over the Chukchi Sea some $120 \mathrm{~km}$ east of the SHEBA ice camp, where the ER-2 is flying from bottom (south) to top (north) up these images along the right-hand-most ground track parallel to the flight track over the SHEBA ice station. MAS visible and near-infrared channels can readily be used to detect clouds and sea ice, and to determine the thermodynamic phase and optical properties of these clouds. The panel on the left $(0.87 \mu \mathrm{m})$ is sensitive both to scattering by clouds and to reflection by the underlying sea ice surface. In the lower portion of this image there are Arctic stratus clouds and a break, or hole, in the clouds. The middle panel $(1.62 \mu \mathrm{m})$ is largely sensitive to the thermodynamic phase of the clouds (ice versus liquid water) and is also useful for retrieving the cloud optical thickness of water clouds over sea ice due to the low reflectance of sea ice at this wavelength (cf. Fig. 8). The water clouds that dominate the bottom part of this image are somewhat brighter than the ice clouds that dominate the top portion, and these ice clouds are themselves somewhat brighter than the underlying sea ice surface. At $1.88 \mu \mathrm{m}$ (right-hand panel), the low-

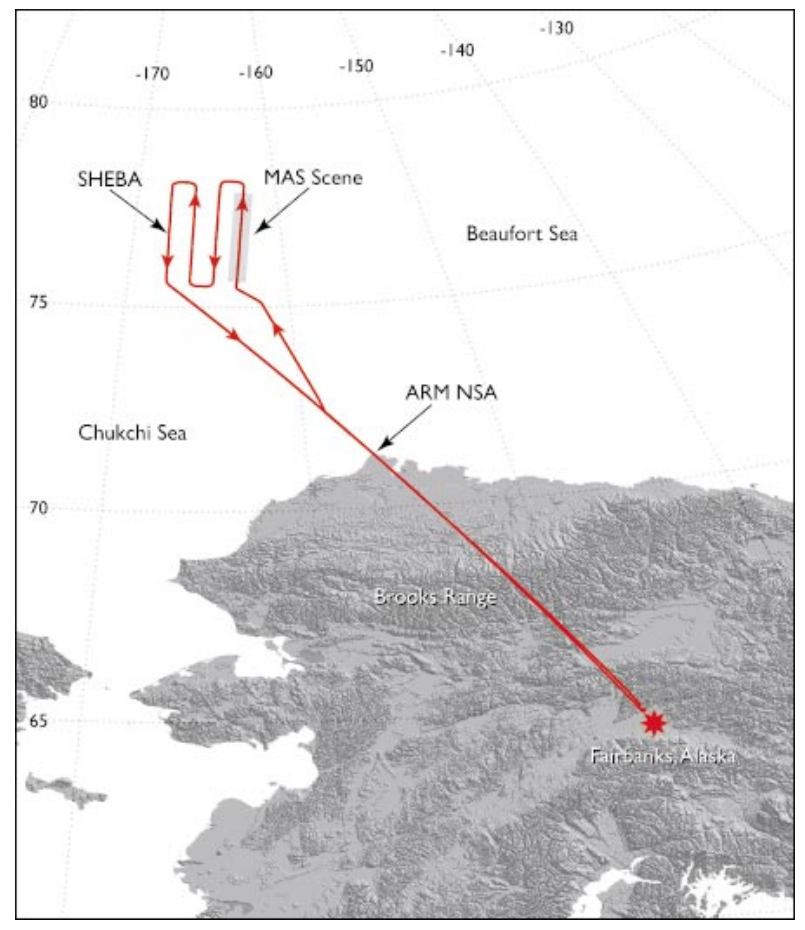

FIG. 9. Ground track of the ER-2 on 4 Jun 1998.

level water clouds are much darker than the midlevel ice clouds. Since this channel is in a strong water vapor absorption channel, these data are especially sensitive to cloud-top altitude and are therefore of value in the cloud mask algorithm described in section 3.

These three channels give only a hint at the wealth of information available in 50-channel high spatial resolution data. Figure 11 shows a false-color composite image of this scene, together with images of the cloud mask, cloud mask tests, and final thermodynamic phase determination applied to this scene. The false-color image was constructed by contrast stretching and combining three spectral bands into one 24-bit image, where the spectral bands were assigned to red, green, and blue (RGB) 8-bit display channels. For this scene, the RGB assignment was 1.62 (red), 0.87 (green), and $1.88 \mu \mathrm{m}$ (blue), corresponding to the same channels presented in Fig. 10. In this manner the midlevel ice clouds appear blue, low-level water clouds appear yellow or orange, and clear sky or sea ice appear green.

The second panel in Fig. 11 represents the results of the cloud mask applied to this scene. As discussed in the previous section, the cloud mask assigns four levels of clear-sky "confidence" to each pixel. In this panel, the high-confidence clear-sky image on which the cloud mask is superimposed is the MAS reflectance in band $7(0.87 \mu \mathrm{m})$. The cloud mask results are designated as cloudy, probably cloudy, probably clear, and high-confidence clear. Comparing the cloud mask results to the false color image on the left in Fig. 11, it appears that 

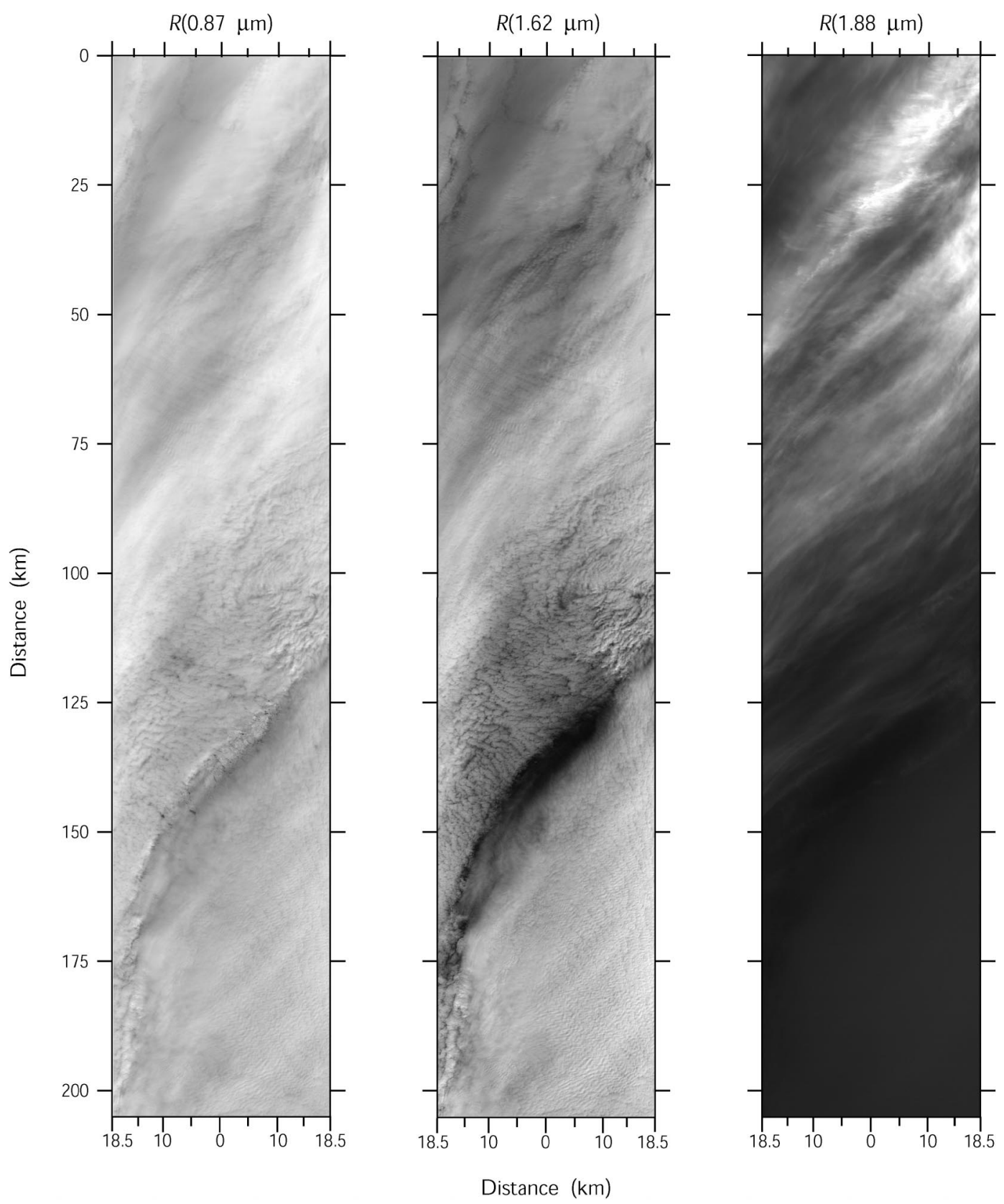

FIG. 10. MAS images of a $205 \mathrm{~km} \times 37 \mathrm{~km}$ section of a north-south flight line some $120 \mathrm{~km}$ due east of the SHEBA ice station on 4 Jun 1998 (5834 scanlines between 2047:00 and 2102:36 UTC). At 0.87 $\mu \mathrm{m}$ it is difficult to distinguish the bright sea ice surface from overlying stratus or altocumulus clouds. At $1.62 \mu \mathrm{m}$, on the other hand, surface reflectance and thin ice clouds have lower reflectance than water clouds or thick ice clouds. At $1.88 \mu \mathrm{m}$, high-level cirrus clouds are readily distinguishable from the surface and low-level water clouds.

both the low-level water clouds in the bottom portion of the image and the midlevel ice clouds in the top portion of the image are being correctly identified as clouds. In the central portion of this image, on the other hand, the openings in the clouds are being correctly identified as clear sky while other portions of thin cloud around the openings are being classified as probably cloudy.
Having determined the cloud mask for this scene, we ran the thermodynamic phase algorithm that makes use of individual cloud mask tests (cf. Fig. 2) to determine a first guess at the thermodynamic phase of the cloudy pixels. These results, shown in the third panel of Fig. 11 , yield a high confidence of ice clouds in the northern half of the scene and liquid water clouds in the southern half of the scene, with a number of pixels of undeter- 


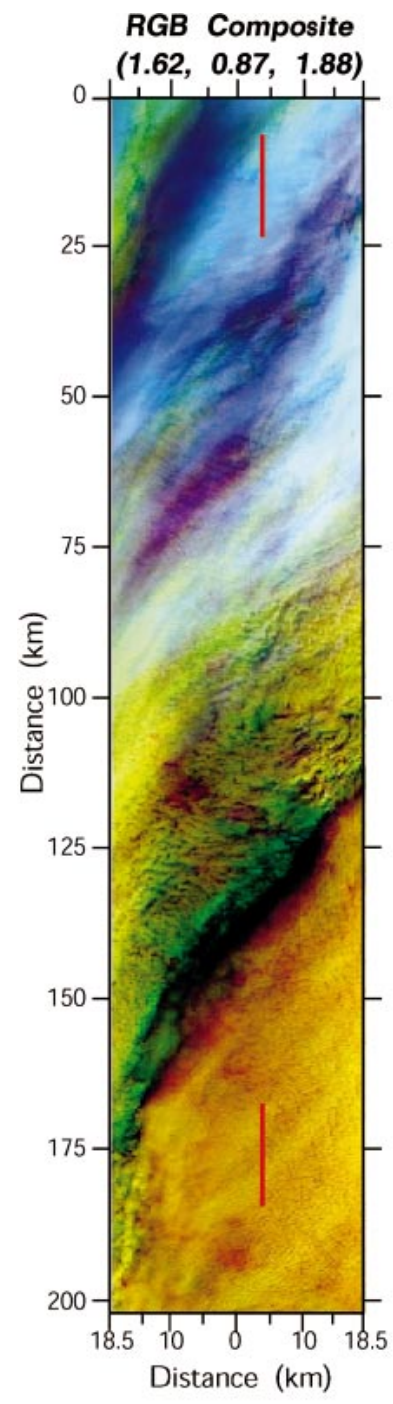

RGB Composite $(1.62,0.87,1.88)$

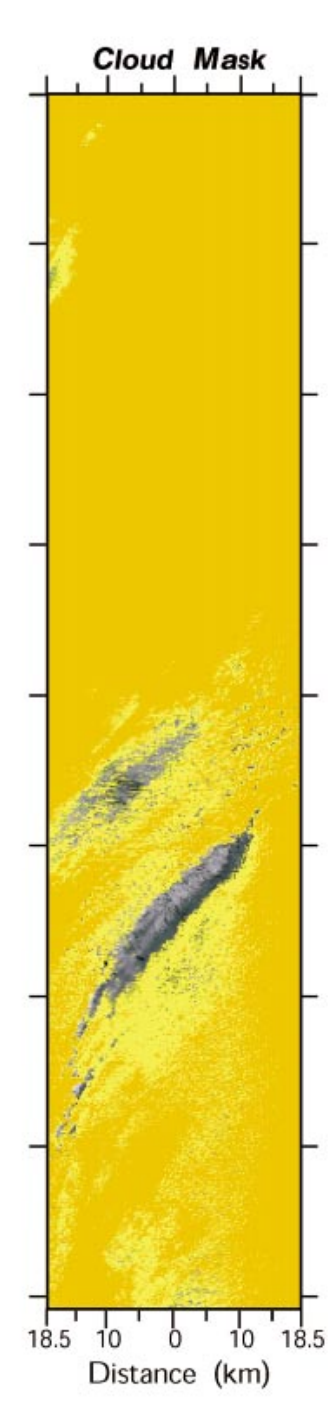

Cloud Mask

Cloudy

Probably Cloudy

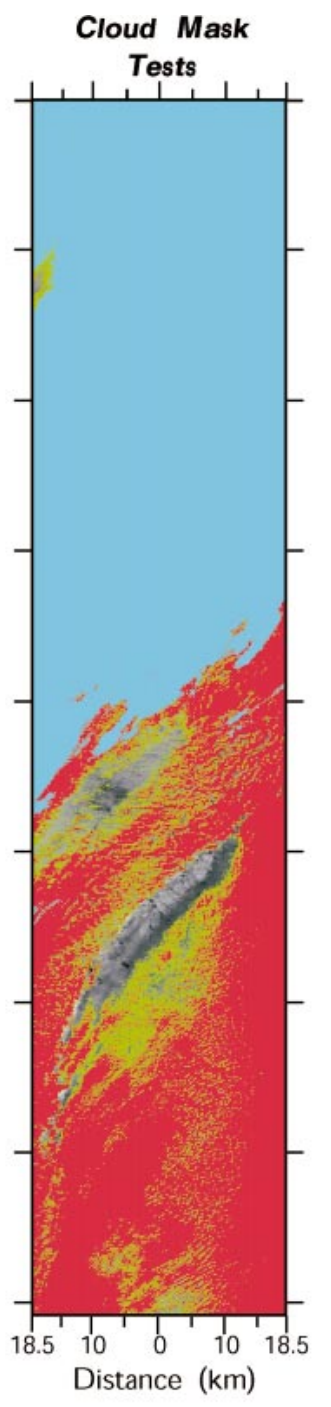

Thermodynamic

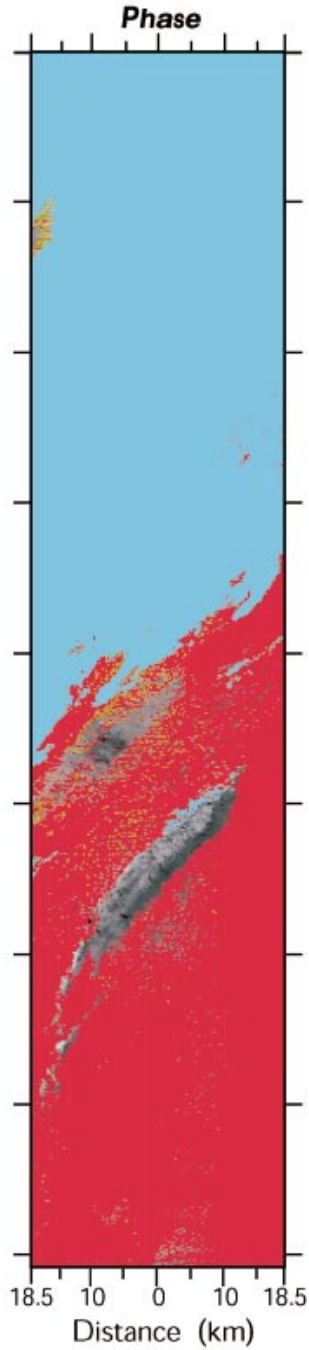

Thermodynamic Phase

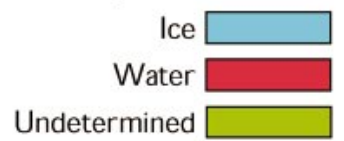

Undetermined

FIG. 11. (left) Composite image of Arctic stratus, altocumulus, and sea ice on 4 Jun 1998. The RGB assignment is red $(1.62 \mu \mathrm{m})$, green $(0.87 \mu \mathrm{m})$, and blue $(1.88 \mu \mathrm{m})$, and is based on the individual channels shown in Fig. 7. The second panel is the resultant cloud mask, the third panel the phase decision based on selected cloud mask tests, and the final panel the final cloud phase decision after applying the bispectral and shortwave infrared tests. The background image on which the cloud mask is overlaid is the MAS reflectance image at $0.87 \mu \mathrm{m}$. The red lines in the false-color image correspond to data points in the water and ice clouds overlaid on the theoretical curves in Figs. 7 and 8.

mined phase occurring primarily in regions where the cloud mask suggested probably cloudy pixels.

Finally, we ran the bispectral $(8.38$ and $10.71 \mu \mathrm{m})$ threshold algorithm for undetermined phase pixels, and shortwave infrared tests for all pixels, as described in section $3 \mathrm{~b}$ and Fig. 3. The final result, shown in the right-hand panel of Fig. 11, indicates that the upper portion of the cloud in this scene was identified as ice cloud while the lower portion of the cloud was identified as liquid water, with very few remaining pixels identified as undetermined phase. These phase results are used for the processing path of all subsequent cloud optical property retrievals.

Though the cloud lidar system failed to work on this flight, making it difficult to unambiguously identify cloud layers and multilayer clouds, it appears from the multispectral imagery of Figs. 10 and 11 that the top portion of the image, identified as ice cloud, is most 
likely a multilayer cloud with ice clouds overlaying a lower-level Arctic stratus or possibly altostratus layer. As the upper-layer cloud was the dominant feature identified in the multispectral imagery, it is this processing path that was used to estimate cloud optical properties in all subsequent analysis. As described by Shupe et al. (2001) from $1 \mathrm{yr}$ of ground-based radar observations of Arctic clouds from the SHEBA ice station, it is uncommon for Arctic clouds to be single-level water or ice clouds, with either multilayer or mixed-phase clouds occurring some $58.2 \%$ of the time during June. The northern portion of this flight track appears to be composed of multilayer clouds, which we will subsequently analyze using the dominant ice cloud libraries characteristic of the uppermost cloud layer (see below).

\section{b. Cloud optical and microphysical properties}

Having identified the corresponding scene as liquid water or ice cloud, we performed cloud optical property retrievals as described in section 3d. Figure 12 shows retrievals of cloud optical thickness and effective radius derived using the retrieval algorithms illustrated in Figs. 7 and 8 for the solar and viewing geometries appropriate to this scene, where the left-hand pair of figures corresponds to the 0.87 - and $2.13-\mu \mathrm{m}$ algorithm and the right-hand pair of figures to the 1.62- and 2.13- $\mu \mathrm{m}$ algorithm. The data points superimposed in Figs. 7 and 8 correspond to southern and northern portions of the flight line that were identified as containing liquid water or ice clouds in Fig. 11. As expected, the effective radius retrievals yield rather similar results between the two algorithms, with the ice cloud particles being quite small in the Arctic region, and where the smallest sizes generally occur for the optically thickest ice clouds in this scene. The failure of the 0.87 - and $2.13-\mu \mathrm{m}$ retrieval in the optically thin northwest portion of this scene occurs because the measured reflection function at $0.87 \mu \mathrm{m}$ is less than the theoretical calculations allow when $A_{g}(0.87$ $\mu \mathrm{m})=0.6$. This is no doubt the consequences of leads and breaks in the sea ice in this region such that the actual underlying surface albedo is much less than 0.6. This only serves to emphasize the difficulty of using the traditional wavelengths to derive cloud optical thickness and effective radius over a spatially nonuniform sea ice (or snow) surface.

The cloud optical thickness in the traditional 0.87 and $2.13-\mu \mathrm{m}$ algorithm is especially sensitive to assumptions on the underlying surface albedo, as expected from the computations presented in Fig. 7. King (1987) demonstrates that for optically thick clouds for which asymptotic theory applies $\left(\tau_{c} \geq 9\right)$, the derived optical thickness depends explicitly on $A_{g}$ such that uncertainties in surface albedo cause a systematic offset in the derived optical thickness by an amount given by $4 A_{g} /$ $3(1-g)\left(1-A_{g}\right)$, where $g$ is the asymmetry factor, defined as the mean cosine of the scattering angle obtained by integrating over the complete scattering phase function ( $\sim 0.85$ for water clouds). This offset is such that the retrieved optical thickness retrieval for $A_{g}=$ 0.5 (0.7) would be 4.44 greater (7.41 smaller) than that for $A_{g}=0.6$. However, as the surface albedo increases to 0.7 and beyond, an increasingly large number of pixels fail the cloud retrieval algorithm because the measured reflectance at $0.87 \mu \mathrm{m}$ is less than the smallest values expected from theoretical calculations. As a consequence of the uncertainties and variability in the underlying surface albedo of snow and sea ice surfaces at visible wavelengths, the Platnick et al. (2001) algorithm that combines two shortwave infrared bands (1.62 and $2.13 \mu \mathrm{m}$ ) is especially attractive for cloud optical property retrievals for water clouds. This technique is less sensitive to cloud optical properties of ice clouds due to the strong absorption characteristics of sea ice and ice particles, but both algorithms yield rather similar results for effective radius, even for ice clouds.

A numerical comparison of the two cloud retrieval algorithms can best be seen by examining histograms of retrieved cloud optical properties. Figure 13a shows comparisons of the marginal probability density function of cloud optical thickness for all liquid water clouds in this scene, with Fig. 13b showing the corresponding probability density of effective radius. Figures $13 \mathrm{c}$ and $13 \mathrm{~d}$ show corresponding probability density functions for all ice clouds in this scene, where we have used the same abscissa scale as in Figs. 13a and 13b. Note that a high optical thickness mode $\left(\tau_{c} \geq 100\right)$ is not shown on this scale. Though biases clearly exist in the cloud optical thickness retrieval, the effective radius is retrieved quite consistently in both cases. Based on this analysis as well as other retrievals using MAS data in the Arctic (not shown), the 1.62- and 2.13- $\mu \mathrm{m}$ algorithm first described by Platnick et al. (2001) would appear to be a promising algorithm for routine cloud optical property retrievals over snow and sea ice surfaces during the daytime. This algorithm will soon be adapted to MODIS retrievals over these ecosystems for Terra data, though the $1.64-\mu \mathrm{m}$ band on Aqua/MODIS is not reliable.

\section{Summary and conclusions}

High-resolution images of the spectral reflection function and thermal emission of the earth-atmosphere system were obtained with the MODIS Airborne Simulator (MAS) operated from the NASA ER-2 aircraft during the intensive field component of the FIRE ACE experiment, conducted over the Beaufort and Chukchi Seas of the Arctic Ocean between 18 May and 6 June 1998. Multispectral images of the reflectance and brightness temperature at 10 wavelengths between 0.66 and 13.98 $\mu \mathrm{m}$ were used to derive the probability of clear sky (or cloud), cloud thermodynamic phase, and the optical thickness and effective radius of liquid water and ice clouds over sea ice in the high Arctic during summer. We compared two separate algorithms for determining 


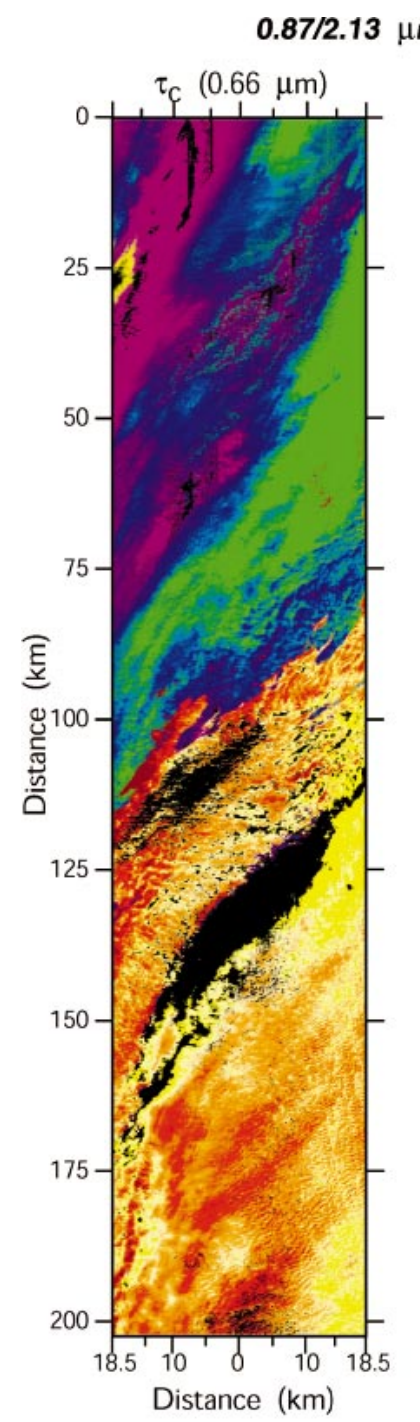

\subsection{2/2.13 $\mu \mathrm{m}$ Algorithm}
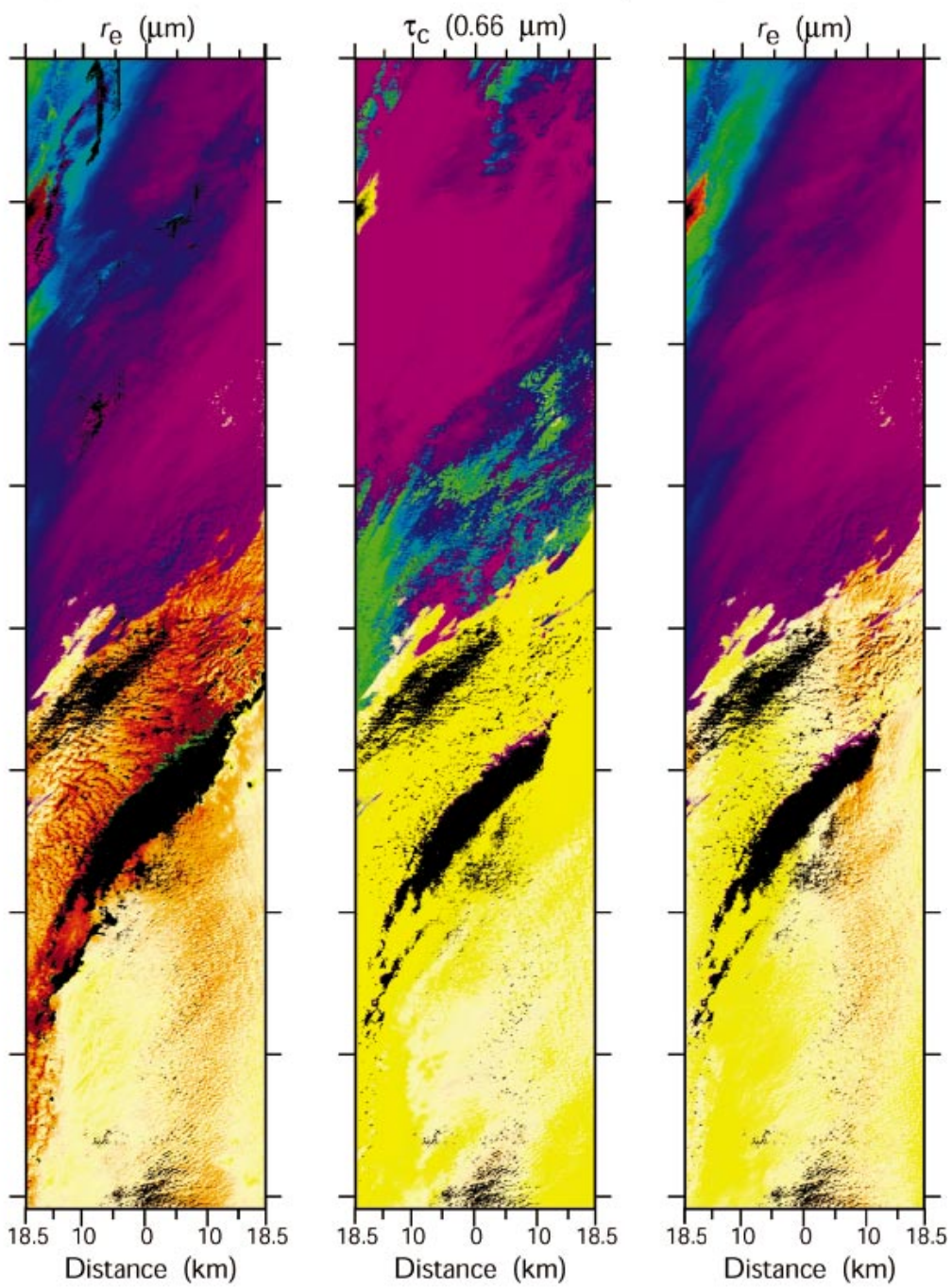

Distance $(\mathrm{km})$
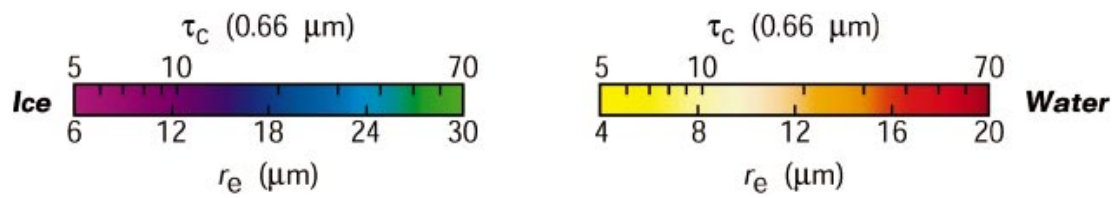

FIG. 12. Cloud optical thickness and effective radius derived from the MAS images on 4 Jun 1998. The pair of images on the left corresponds to the 0.87 - and $2.13-\mu \mathrm{m}$ algorithm, and the pair of images on the right corresponds to the same scene analyzed using the 1.62- and 2.13- $\mu \mathrm{m}$ algorithm. In all cases, we have used a split color bar to designate those pixels analyzed using the liquid water and ice cloud processing path.

the cloud optical thickness and effective radius: one closely aligned to the version run operationally to process MODIS data on the Terra and Aqua spacecraft, and the other a more recent algorithm that uses the 1.62and 2.13- $\mu \mathrm{m}$-band combination.

The 1.62- and $2.13-\mu \mathrm{m}$ algorithm is more robust at determining the cloud optical thickness and effective radius for water clouds over snow and sea ice surfaces, due primarily to the fact that both snow and sea ice have very low surface reflectance at these wavelengths. As a consequence, liquid water clouds provide a relatively strong reflectance contrast to the dark underlying surface. This algorithm is less reliable for ice clouds due to the strong absorption by ice particles in both of these bands.

In this paper we also describe the thermodynamic phase algorithm that is nearly identical to that implemented in the global processing of MODIS data from the Terra and Aqua spacecraft. Both in MAS processing during FIRE ACE and in global processing of MODIS 


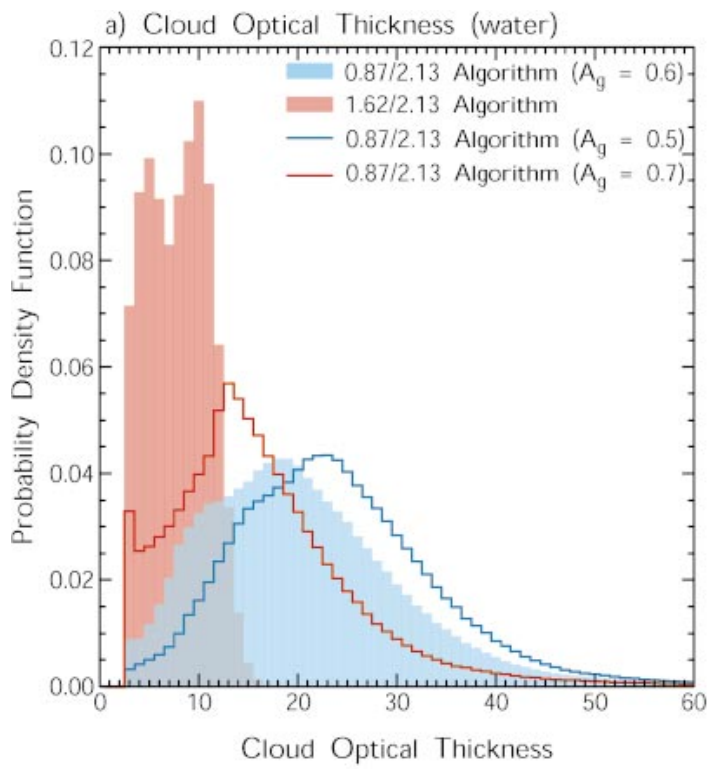

b) Cloud Effective Radius (water)
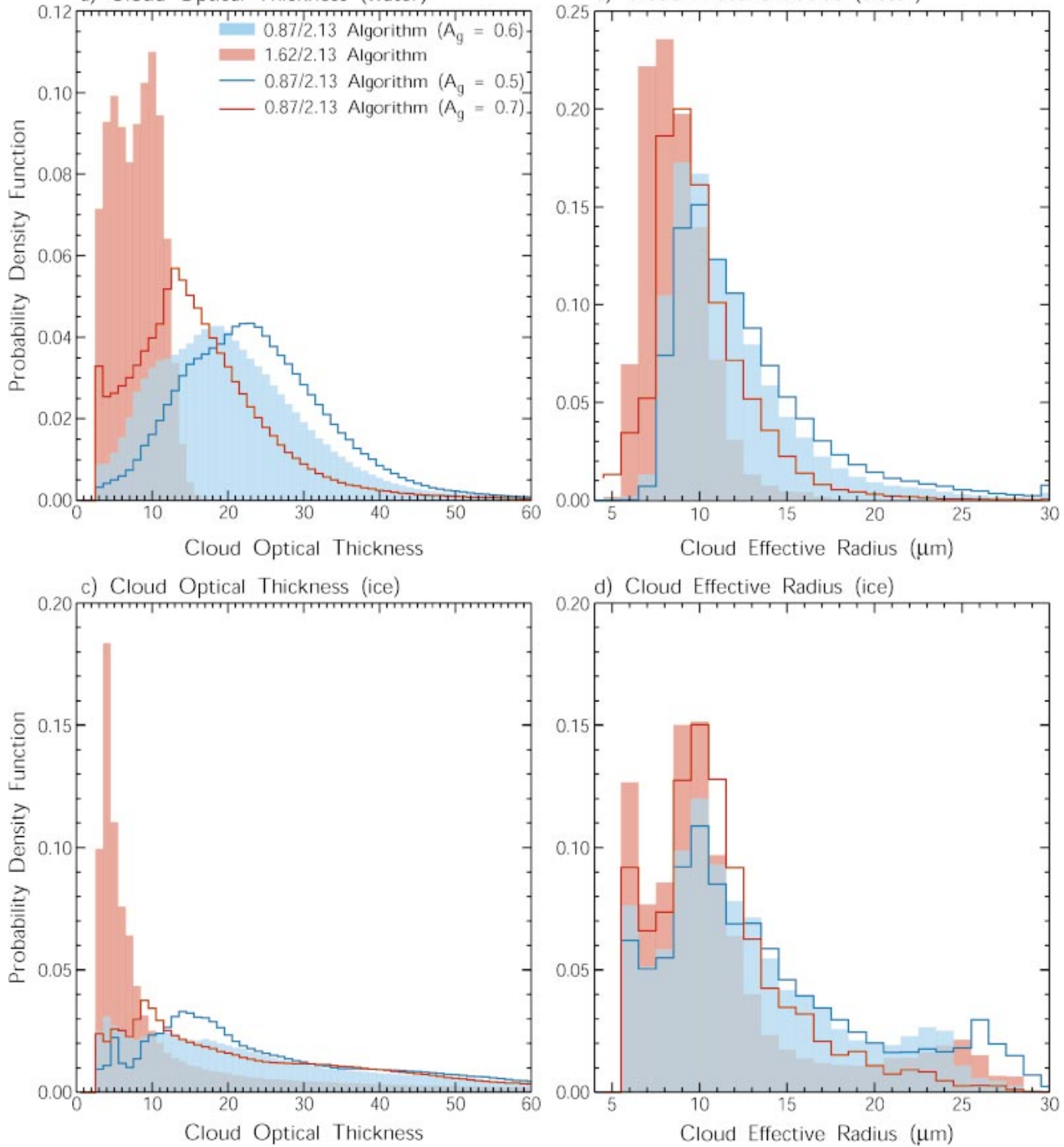

d) Cloud Effective Radius (ice)

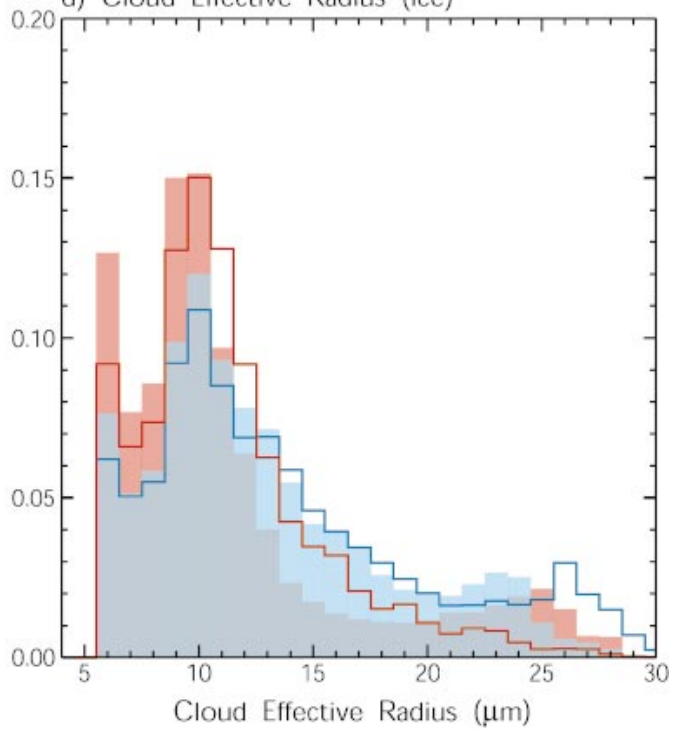

FIG. 13. Marginal probability density function of cloud optical thickness and effective radius for all (a), (b) water and (c), (d) ice pixels in the MAS flight line on 4 Jun 1998. The pair of probability density functions in each panel corresponds to the probability distribution of cloud retrievals for the $0.87-$ and $2.13-\mu \mathrm{m}$ algorithm (blue distribution) and the 1.62- and 2.13- $\mu \mathrm{m}$ algorithm (red distribution). The distributions arising from changing the surface albedo at $0.87 \mu \mathrm{m}$ from 0.6 to 0.5 or 0.7 are shown as solid curves in all panels.

data, we characterize the optical properties of nonspherical ice clouds using 12 different size distributions, ice crystal habit that is a function of particle size, and stateof-the-art light-scattering models. These ice crystal characteristics, all described herein, have thus far proven to be robust in global processing of MODIS data and are likely to be extendable to more advanced ice crystal models currently under development. The main difference at present is that MODIS utilizes the reflectance at $1.24 \mu \mathrm{m}$ for retrieving cloud optical thickness over snow and sea ice surfaces, rather than $0.87 \mu \mathrm{m}$ as described in this paper. This wavelength, which is avail- able on MODIS but not on MAS, has a smaller surface reflectance for dry snow (0.45) and wet snow or sea ice $(0.25)$ than $0.87 \mu \mathrm{m}$, and so is preferable for MODIS processing of cloud optical and microphysical properties. In the future we plan to implement the 1.63- and 2.13- $\mu \mathrm{m}$ algorithm for Terra/MODIS processing of water clouds over snow and sea ice surfaces.

Acknowledgments. The research reported in this article was supported by the MODIS Science Team and NASA's Radiation Sciences Program. SAA was supported by NASA Contract NAS5-31367 to the Univer- 
sity of Wisconsin-Madison, and PY and KNL were supported by NASA Grant NAG 5-6160 to the University of California, Los Angeles. We would like to express our appreciation to G. Wind for data analysis and visualization support, J. S. Myers and M. Fitzgerald for MAS deployment support, and B. A. Baum and S. L. Nasiri for valuable discussions on the thermodynamic phase algorithm.

\section{REFERENCES}

Ackerman, S. A., K. I. Strabala, W. P. Menzel, R. A. Frey, C. C Moeller, and L. E. Gumley, 1998: Discriminating clear sky from clouds with MODIS. J. Geophys. Res., 103, 32 141-32 157.

- , and Coauthors, cited 2002: Discriminating clear-sky from clouds with MODIS algorithm theoretical basis document (MOD35). Goddard Space Flight Center, 112 pp. [Available online at modis-atmos.gsfc.nasa.gov/_docs/atbd_mod06.pdf]

Armstrong, R. L., and M. J. Brodzik, 2002: Hemispheric-scale comparison and evaluation of passive-microwave snow algorithms. Ann. Glaciol., 34, 38-44.

Arnold, G. T., S. C. Tsay, M. D. King, J. Y. Li, and P. F. Soulen, 2002: Airborne spectral measurements of surface-atmosphere anisotropy for Arctic sea ice and tundra. Int. J. Remote Sens., 23, 3763-3781.

Auer, A. H., Jr., and D. L. Veal, 1970: The dimension of ice crystals in natural clouds. J. Atmos. Sci., 27, 919-926.

Baum, B. A., D. P. Kratz, P. Yang, S. C. Ou, Y. Hu, P. Soulen, and S. C. Tsay, 2000a: Remote sensing of cloud properties using MODIS Airborne Simulator imagery during SUCCESS. I: Data and models. J. Geophys. Res., 105, $11767-11780$.

—, P. F. Soulen, K. I. Strabala, M. D. King, S. A. Ackerman, W. P. Menzel, and P. Yang, 2000b: Remote sensing of cloud properties using MODIS Airborne Simulator imagery during SUCCESS. II: Cloud thermodynamic phase. J. Geophys. Res., 105 $11781-11792$.

Chou, M. D., K. T. Lee, and P. Yang, 2002: Parameterization of shortwave cloud optical properties for a mixture of ice particle habits for use in atmospheric models. J. Geophys. Res., 107, 4600, doi:10.1029/2002JD002061.

Cox, C., and W. Munk, 1954: Measurement of the roughness of the sea surface from photographs of the sun's glitter. J. Opt. Soc. Amer., 44, 838-850.

Curry, J. A., and Coauthors, 2000: FIRE Arctic Clouds Experiment. Bull. Amer. Meteor. Soc., 81, 5-30.

Downing, H. D., and D. Williams, 1975: Optical constants of water in the infrared. J. Geophys. Res., 80, 1656-1661.

Fu, Q., 1996: An accurate parameterization of the solar radiative properties of cirrus clouds for climate models. J. Climate, 9, 2058-2082.

Gosse, S., D. Labrie, and P. Chylek, 1995: Refractive index of ice in the 1.4 to $7.8 \mu \mathrm{m}$ spectral range. Appl. Opt., 34, 6582-6586.

Hale, G. M., and M. R. Querry, 1973: Optical constants of water in the 200-nm to 200- $\mu \mathrm{m}$ wavelength region. Appl. Opt., 12, 555563.

Hansen, J. E., and J. B. Travis, 1974: Light scattering in planetary atmospheres. Space Sci. Rev., 16, 527-610.

King, M. D., 1987: Determination of the scaled optical thickness of clouds from reflected solar radiation measurements. J. Atmos. Sci., 44, 1734-1751. and D. D. Herring, 2000: Monitoring Earth's vital signs. Sci. Amer., 282, 72-77.

, and Coauthors, 1996: Airborne scanning spectrometer for remote sensing of cloud, aerosol, water vapor, and surface properties. J. Atmos. Oceanic Technol., 13, 777-794.

_, S. C. Tsay, S. A. Ackerman, and N. F. Larsen, 1998: Discriminating heavy aerosol, clouds, and fires during SCAR-B: Application of airborne multispectral MAS data. J. Geophys. Res., 103, 31 989-32 000.

_ , and Coauthors, 2003: Cloud and aerosol properties, precipitable water, and profiles of temperature and humidity from MODIS. IEEE Trans. Geosci. Remote Sens., 41, 442-458.

Korolev, A., and G. Isaac, 2003: Roundness and aspect ratio of particles in ice clouds. J. Atmos. Sci., 60, 1795-1808.

Loveland, T. R., and A. S. Belward, 1997: The IGBP-DIS global 1 $\mathrm{km}$ land cover data set, DISCover: First results. Int. J. Remote Sens., 18, 3291-3295.

Mitchell, D. L., 2002: Effective diameter in radiation transfer: General definition, applications, and limitations. J. Atmos. Sci., 59, 23302346.

Nakajima, T., and M. D. King, 1990: Determination of the optical thickness and effective particle radius of clouds from reflected solar radiation measurements. Part I: Theory. J. Atmos. Sci., 47, 1878-1893.

Nasiri, S. L., B. A. Baum, A. J. Heymsfield, P. Yang, M. Poellot, D. P. Kratz, and Y. Hu, 2002: Development of midlatitude cirrus models for MODIS using FIRE-I, FIRE-II, and ARM in situ data. J. Appl. Meteor., 41, 197-217.

Palmer, K. F., and D. Williams, 1974: Optical properties of water in the near infrared. J. Opt. Soc. Amer., 64, 1107-1110.

Parkinson, C. L., 2003: Aqua: An Earth-observing satellite mission to examine water and other climate variables. IEEE Trans. Geosci. Remote Sens., 41, 173-183.

Platnick, S., J. Y. Li, M. D. King, H. Gerber, and P. V. Hobbs, 2001: A solar reflectance method for retrieving the optical thickness and droplet size of liquid water clouds over snow and ice surfaces. J. Geophys. Res., 106, 15 185-15 199.

_ - M. D. King, S. A. Ackerman, W. P. Menzel, B. A. Baum, J. C. Riédi, and R. A. Frey, 2003: The MODIS cloud products: Algorithms and examples from Terra. IEEE Trans. Geosci. Remote Sens., 41, 459-473.

Rolland, P., K. N. Liou, M. D. King, S. C. Tsay, and G. M. McFarquhar, 2000: Remote sensing of optical and microphysical properties of cirrus clouds using MODIS channels: Methodology and sensitivity to assumptions. J. Geophys. Res., 105, $11721-$ 11738 .

Shupe, M. D., T. Uttal, S. Y. Matrosov, and A. S. Frisch, 2001: Cloud water contents and hydrometeor sizes during the FIRE Arctic Clouds Experiment. J. Geophys. Res., 106, 15 015-15028.

Strabala, K. I., S. A. Ackerman, and W. P. Menzel, 1994: Cloud properties inferred from $8-12-\mu \mathrm{m}$ data. J. Appl. Meteor., 33, 212-229.

Takano, Y., and K. N. Liou, 1989: Solar radiation transfer in cirrus clouds. Part I: Single-scattering and optical properties of hexagonal ice crystals. J. Atmos. Sci., 46, 3-19.

Warren, S. G., 1984: Optical constants of ice from the ultraviolet to the microwave. Appl. Opt., 23, 1206-1225.

Wyser, K., and P. Yang, 1998: Average ice crystal size and bulk shortwave single-scattering properties of cirrus clouds. Atmos. Res., 49, 315-335.

Yang, P., and K. N. Liou, 1996a: Finite-difference time domain method for light scattering by small ice crystals in three-dimensional space. J. Opt. Soc. Amer., 13A, 2072-2085.

, and _ _ 1996b: Geometric-optics-integral-equation method for light scattering by nonspherical ice crystals. Appl. Opt., 35, 6568-6584. 